\title{
1 Are tropical hummingbird pollination networks resistant to experimental extirpation of a
}

\section{2 common flowering plant?}

3 Kara G. Leimberger ${ }^{1,}$, Adam S. Hadley ${ }^{1,2}$, Sarah J.K. Frey ${ }^{1,3}$, and Matthew G. Betts ${ }^{1}$

$4 \quad{ }^{1}$ Forest Biodiversity Research Network, Department of Forest Ecosystems and Society, Oregon

5 State University, Corvallis, Oregon, USA

$6 \quad{ }^{2}$ Biodiversity Section, Department of Natural Resources and Energy Development, Fredericton,

7 New Brunswick, Canada

$8{ }^{3}$ Department of Animal and Rangeland Sciences, Oregon State University, Corvallis, Oregon,

9 USA

10

11 *Author for correspondence (E-mail: kara.leimberger@ oregonstate.edu). 


\section{ABSTRACT}

Plants and pollinators are experiencing parallel declines worldwide, despite theory predicting that pollination networks should withstand disturbance due to redundancy of pollinators, rarity of interactions between specialists, and flexible pollinator foraging behavior (rewiring). Experiments evaluating the stability of plant-pollinator networks may help resolve this incongruity but remain uncommon. In this study, we simulated the extirpation of a hummingbird-pollinated understory plant, Heliconia tortuosa, from tropical forest fragments using a replicated Before-After-Control-Impact experimental design while quantifying hummingbird space use (383 hummingbird captures and 72 radio-tagged individuals), floral visitation rates (6,759 visitations from 20,725 observation hours), and plant pollination success (529 flowers). To complement this experimental approach, we also examined these responses across a natural gradient in $H$. tortuosa density. We expected that declines of $H$. tortuosa would either result in (a) network collapse, in which hummingbirds vacate fragments and compromise the reproductive success of other flowering plants, or (b) increased hummingbird reliance on alternative resources, leading to sustained fragment use. We also hypothesized that landscape and local context (i.e., connectivity to additional forest area and alternative resource abundance) could mediate hummingbird responses to $H$. tortuosa declines; for example, connectivity could facilitate hummingbird visitation to areas of reduced food availability. In our removal experiment, hummingbird persistence and plant pollination success were remarkably resistant to loss of $H$. tortuosa, a locally common plant species representing $>40 \%$ of the available nectar resources on average. However, naturally low $H$. tortuosa densities were associated with reduced floral visitation rates and decreased pollination. Although landscape context (connectivity) led to higher hummingbird abundance, we found little evidence that connectivity or resource availability mediated hummingbird responses to declines in $H$. tortuosa availability. The exact 
mechanisms enabling short-term hummingbird persistence after resource removal remain

37 unclear, as we did not discover evidence of rewiring. Physiological adaptations (e.g., torpor and insectivory), may have contributed to hummingbird resilience, perhaps alongside high movement abilities that facilitated visitation to spatially dispersed floral resources. With the important caution that short-term experiments may not realistically emulate natural extinction processes, our study provides partial support for theoretical predictions that pollination networks may be relatively robust to plant species loss.

Key words: mutualistic networks, ecosystem function, foraging ecology, functional connectivity, fragmentation, Trochilidae

INTRODUCTION coextinctions of dependent species and declines in ecosystem function (Colwell, Dunn, and Harris 2012; Koh et al. 2004). Linked extinctions may be especially likely for mutualistic interactions, such as those between plants and pollinators (Dunn et al. 2009; Aslan et al. 2013). For instance, plants that are not adequately pollinated produce fewer seeds, accruing extinction

52 debt that becomes realized when the existing generation cannot be replaced by new recruits

53 (Ashman et al. 2004; Vellend et al. 2006; Kuussaari et al. 2009). This repeated reproductive

54 failure will eventually cause demographic collapse of plant populations (Anderson et al. 2011;

55 Phillips et al. 2015), which could then hasten the decline of animals that consume pollen or nectar (Biesmeijer et al. 2006; Pauw and Hawkins 2011; Weiner et al. 2014; Scheper et al. 2014).

57 Indeed, plants and pollinators are experiencing declines worldwide (Biesmeijer et al. 2006; Potts 
which humans depend but also threatens the maintenance of global biodiversity (Allen-Wardell

60

61

62

et al. 1998; Klein et al. 2007; Ollerton, Winfree, and Tarrant 2011).

Although the underlying reasons for plant and pollinator declines are not fully understood, one prominent hypothesis invokes the landscape-level processes of habitat loss and fragmentation (Kearns, Inouye, and Waser 1998; Aguilar et al. 2006; Potts et al. 2010; Hadley and Betts 2012). Habitat destruction often creates small habitat patches unable to sustain large populations, which can increase rates of local extinction (Hanski 1998), reduce functional connectivity (sensu P. D. Taylor et al. 1993), and impede pollinator movement (Hadley and Betts 2012). Likely due to these combined mechanisms, land-use change and habitat isolation have been repeatedly linked to declines in pollinator diversity (Winfree, Bartomeus, and Cariveau 2011; Montero-Castaño and Vilà 2012; Senapathi et al. 2015) and plant reproduction (Steffan-Dewenter and Tscharntke 1999; Taki, Kevan, and Ascher 2007; Farwig et al. 2009; Garibaldi et al. 2011).

However, parallel declines of pollinators and plants are at odds with theoretical predictions suggesting that species loss should generally not result in coextinction of interaction partners (Memmott, Waser, and Price 2004; Bascompte, Jordano, and Olesen 2006). Tolerance to subsequent extinctions (i.e., robustness) primarily arises from the expectation that interaction networks exhibit strongly nested topologies, such that specialists interact with subsets of partners linked to generalists (Bascompte et al. 2003). Under this interaction pattern, connections between specialists are uncommon, so the functional role of a specialist can be absorbed by its more abundant generalist partners (Bascompte et al. 2003; Bascompte and Jordano 2007). In addition to the redundancy afforded by a nested structure, models suggest that flexibility in pollinator foraging behavior - i.e., rewiring to use alternative resources - may buffer networks against 
82 disturbance (Kaiser-Bunbury et al. 2010; Ramos-Jiliberto et al. 2012; Valdovinos et al. 2013;

83 Timóteo et al. 2016).

Despite these overall predictions and mechanisms of robustness, pollination networks

85 may be vulnerable to habitat loss and fragmentation under certain conditions. Although systematic loss of generalist pollinators may be less realistic than extinctions of rare, specialist

87 pollinators (Aizen, Sabatino, and Tylianakis 2012), simulation studies have revealed that removal of highly connected, generalist species thwarts a network's capacity to buffer perturbations, leading to rapid partner extinction (Memmott, Waser, and Price 2004; KaiserBunbury et al. 2010; Traveset, Tur, and Eguíluz 2017). Thus, if external stressors such as habitat fragmentation threaten highly connected species ('topological keystones' sensu Jordán 2009), an

92 extinction cascade could occur - particularly without rewiring by pollinators. However, uncertainty about the robustness of real-world plant-pollinator networks still exists because

94 relatively few studies have quantified pollinator responses to deletions of other species

95 (Appendix S1: Table S1).

In this study, we tested whether declines of a hummingbird-pollinated plant (Heliconia

97 tortuosa) could have cascading consequences for communities of hummingbirds and flowering

98 plants within a fragmented tropical forest landscape - or whether rewiring might forestall

99 network collapse. In Neotropical forests, the genus Heliconia (Heliconiaceae) comprises understory herbs that have been suggested to function as "keystone mutualists" (Gilbert 1980).

101 Large, brightly colored Heliconia inflorescences not only provide nectar to large-bodied hermit 102 hummingbirds (Trochilidae: Phaethornithinae) throughout the year, but also support a variety of other hummingbird species during periods of resource scarcity (Stiles 1975; 1985). Because most

104 hummingbird species visit multiple plant species (Rodríguez-Flores et al. 2019), loss of $H$. 
tortuosa and its associated hummingbird partners could jeopardize the reproduction of cooccurring plants, thus generating an extinction cascade (Gilbert 1980). Although H. tortuosa is locally common in the mid-elevation, premontane tropical forests of Costa Rica, Hadley et al. (2014) found that $H$. tortuosa in smaller forest fragments produced fewer seeds, possibly due to short-distance pollen transfer associated with pollinator movement limitation. Although numerous hummingbird species visit $H$. tortuosa opportunistically, its primary pollinators are the green hermit (Phaethornis guy) and violet sabrewing (Campylopterus hemileucurus) (Stiles 1979; Wolf and Stiles 1989; J. Taylor and White 2007; Betts, Hadley, and Kress 2015). These relatively large, forest-associated hummingbirds are high-reward trapliners (sensu Feinsinger and Colwell 1978) that visit spatially dispersed, nectar-rich floral resources in a routine sequence (Borgella, Snow, and Gavin 2001). However, their movements become restricted in fragmented habitats (Hadley and Betts 2009; Volpe et al. 2016; Kormann et al. 2016).

To assess the potential consequences of $H$. tortuosa declines, we measured hummingbird space use, floral visitation rates, and plant pollination success before and after temporary experimental removal of $H$. tortuosa within forest fragments. Additionally, we assessed how these responses varied across a natural gradient in Heliconia density. We developed two alternative hypotheses about how hummingbirds would respond to declines of $H$. tortuosa (hereafter Heliconia) and potentially affect the pollination of co-occuring plant species (Table 1). Under the robust network hypothesis (H1a), hummingbirds do not emigrate from forest fragments following Heliconia decline, leading to uninterrupted visitation to remaining plants. Under this scenario, we hypothesized that hummingbirds compensate for Heliconia extinction by increasing their use of non-Heliconia floral resources (rewiring). Alternatively, hummingbirds may be highly dependent on $H$. tortuosa and inflexible in their foraging choices; therefore, local 
Heliconia declines should reduce nectar availability such that hummingbirds cannot afford the energetic costs to remain in (or travel to) focal forest fragments, leading to decreases in fragment use and pollination success (H1b: parallel extinction hypothesis). Under both hypotheses, we expected hummingbirds to change their behavior due to their exceptionally rapid metabolisms, high dependency on nectar, and limited fat stores (Suarez 1992; Powers, Brown, and Van Hook 2003). Additionally, we hypothesized that landscape and local context could mediate the influence of Heliconia declines on hummingbird behavior (Table 1). Connectivity to additional forest area (connectivity hypothesis, H2) may sustain hummingbird fragment use by facilitating travel to fragments (rescue hypothesis, H2a) or promote steeper declines in fragment use by facilitating hummingbird departure (abandonment hypothesis, H2b). Further, greater local availability of non-Heliconia floral resources may promote hummingbird persistence through increased opportunities for rewiring (resource hypothesis, H3). Lastly, we expected that changes in Heliconia density would affect green hermits and violet sabrewings more strongly than other hummingbird species (H4). Green hermits and violet sabrewings (hereafter 'Heliconia specialists') inhabit the forest understory, have bills that are morphologically specialized to long, curved $H$. tortuosa flowers, and are thought to visit $H$. tortuosa more frequently than other hummingbirds (Borgella, Snow, and Gavin 2001; Betts, Hadley, and Kress 2015).

To our knowledge, this study not only constitutes one of most highly replicated, largescale removal experiments conducted within the context of plant-pollinator interaction networks (Appendix S1: Table S1), but also represents the first test of how landscape and local context influence hummingbird responses to declines in a common floral resource. Importantly, understanding mechanisms of pollinator persistence in fragmented landscapes has implications for conservation planning, since fragmentation effects may be ameliorated by habitat restoration, 
151 preservation of riparian corridors, and/or implementation of living fences (Renjifo 2001;

152 Kormann et al. 2016).

153 METHODS

154 Study area

155 This study was conducted in southern Costa Rica within a $\sim 122 \mathrm{~km}^{2}$ area surrounding the Las

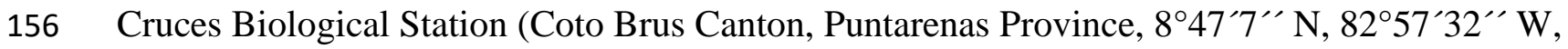

157 Fig. 1: A-B). This study area comprises cattle pastures, coffee plantations, and fragments of

158 tropical premontane wet forest created during a period of extensive land clearing concentrated

159 between 1960 and 1980 (Zahawi, Duran, and Kormann 2015). Remnant forest fragments ( 30\%

160 of the study area) span a wide range of sizes ( $<1$ to $>1000 \mathrm{ha}$ ), with otherwise isolated fragments

161 often connected by narrow riparian corridors and living fences (Hadley and Betts 2009; Zahawi,

162 Duran, and Kormann 2015). Mean annual temperature at the Las Cruces Biological Station is

$163 \sim 21^{\circ} \mathrm{C}$, mean annual rainfall is $3500-4000 \mathrm{~mm}$, and a dry season occurs from December to

164 March (Borgella, Snow, and Gavin 2001; Zahawi, Duran, and Kormann 2015).

165 Study sites

We selected 14 focal fragments embedded within focal landscapes of 1000 m radius

167 ('sites', Fig. 1: A, C). We chose the spatial extent of focal landscapes a priori based on the 168 maximum estimated daily movement distance for large, forest-associated hummingbird species

169 in this study system (Volpe et al. 2014). We identified potential sites using a stratified design

170 with two categories: 'connected to forest' or 'unconnected to forest', based on visual

171 examination of satellite imagery and previous work in this study area (Hadley et al. 2014; 2018;

172 Kormann et al. 2016). This design was only for site establishment, as we later quantified

173 connectivity as a continuous variable (see 'Quantifying connectivity' below). Sites were then 
174 included based on presence of flowering Heliconia, landowner permission, vehicle accessibility,

175 and navigable terrain. To ensure site accessibility, we conducted our study during the dry season

176 and beginning of the rainy season (February - May), because localized flooding can occur during

177 periods of heavy rainfall. Elevation of sites ranged from 900-1500 m (Appendix S2: Table S1).

\section{Study design}

Using the 14 focal-patch landscapes, we repeated the Heliconia removal experiment 16

Heliconia removal, and we designated the other site as a control $(N=16$ control replicates, $N=$ 

term changes to floral resources associated with destructive sampling methods (e.g., cutting). variables').

\section{Response variables}

Within each focal area, we captured hummingbirds at the beginning and end of the

214 experimental period (Fig. 2A) by deploying 5 - 20 mist nets (12-m and 6-m in length) near

215 flowering plants visited by hummingbirds (e.g., the genera Heliconia, Centropogon, Palicourea,

216 Musa). Nets were opened 30 minutes after sunrise and remained open for 2 - 5 hours per session.

217 Capture effort (net-hours) and net locations were kept constant for both capture sessions, except

218 in one instance (Appendix S2: Figure S1). Following the North American Banding Council's 
220

221

222

223

224

225

226

227

228

229

230

231

232

233

234

235

236

237

238

239

240

241

242

tarsus band, measured body mass to the nearest $0.01 \mathrm{~g}$ using an electronic balance, and measured wing length to the nearest $0.5 \mathrm{~mm}$ using a wing rule. Tarsus bands allowed detection of recaptured hummingbirds within and between capture sessions; individuals recaptured during the same capture session were only counted once. In 2017-2018, we also marked hummingbirds' heads with unique color combinations of nail polish following Hadley et al. (2014); this additional mark allowed us to identify individual hummingbirds seen on trail cameras (see 'Camera observations'). All birds were handled in accordance with Oregon State University Animal Care and Use Protocols (ACUP \#4655, \#5015).

\section{Radio telemetry}

We attached miniaturized radio transmitters $(0.15-0.25 \mathrm{~g}$, Blackburn Transmitters, Nacogdoches, TX) to 72 hummingbirds according to the methods of Hadley \& Betts (2009). We then followed hummingbirds on foot using portable receivers (Wildlife Materials Inc TRX 1000S) and handheld Yagi antennae, recorded locations continuously when the bird was found within receiver range ( $250 \mathrm{~m}$ in the absence of topographical barriers). In total, we completed 447 hours of telemetry observation, averaging $3.1 \pm 0.8$ hours per session (typically 8:00-11:00) and $5.3 \pm 0.9$ sessions per site (mean $\pm \mathrm{SD}$ ). From the recorded locations, we estimated the proportion of observation time that radio-tagged birds spent in the focal area (Appendix S2). Thirty-six hummingbirds spent time in the focal area during the 'pre' period and were included in analyses of the Heliconia removal experiment; for a comprehensive summary of radio-

$$
\text { tracking outcomes, see Appendix S2 (Table S4). }
$$

\section{Floral visitation rates}

To understand hummingbird resource use within each site and to monitor for the presence of marked hummingbirds, we positioned trail cameras (PlotWatcher Pro, Day 6 Outdoors) near 
243 inflorescences of plant species known or suspected to be visited by hummingbirds. Effort within

244 each site was concentrated at two locations ('stations', Fig. 1D) located on roughly opposite ends

245 of the focal area (mean \pm SD distance between stations: $60 \pm 44 \mathrm{~m}$ ). Stations were centered

246 around a focal Heliconia plant that we expected to flower throughout the experimental period,

247 was not in an extremely steep area, and was $>10 \mathrm{~m}$ from the fragment edge. The two focal

248 Heliconia plants remained uncovered throughout the entire experimental period to assess how

249 visitation rates changed after declines in surrounding Heliconia density. To partially standardize

250 plant species composition between control and treatment replicates, we added a floral array

251 comprising 3-5 additional plant species at each station (see Appendix S2: Table S5 and

252 'Pollination success').

253 Trail cameras took one photograph per second during daylight hours (5:30-17:30) and

254 automatically combined these photographs into a time-lapse video. We reviewed videos for

255 hummingbird sightings using the motion detection program MotionMeerkat (Weinstein 2015) or

256 by manually watching the sped-up video. When hummingbirds were detected on camera, we

257 identified the species, recorded any color marks, and noted whether they visited any flowers.

258 From video, we also recorded the number of open flowers available per day. Dates with no

259 available flowers were excluded from analysis, yielding 20,735 total hours of video (Appendix

260 S2: Table S6).

261 Pollination success

262 To investigate whether Heliconia declines influenced pollination success, we examined

263 styles for the presence of pollen tubes, which indicate pollen grain germination and subsequent

264 growth toward the flower ovule(s) (Kearns and Inouye 1993). We focused our pollen tube

265 investigation on the two focal Heliconia plants per replicate, as well as several species from the 
focal arrays (Appendix S2: Table S5). Throughout the experimental period, we collected flowers

267 from these focal plants every 1-2 days, which corresponds to the maximum floral longevity for most of the selected species (Heliconia tortuosa, Hamelia patens: Stratton 1989; Stachytarpheta frantzii: Thomas-Granger 2003). Styles were fixed in formalin-acetic acid-alcohol for at least 24

270 hours, stained with aniline blue, and examined for pollen tubes using epifluorescence microscopy

271 (Kearns and Inouye 1993; Betts, Hadley, and Kress 2015). Due to low pollen tube presence

272 and/or challenges with pollen tube visualization, we were only able to analyze two plant species:

273 H. tortuosa $(\mathrm{N}=327$ styles $)$ and H. patens $(\mathrm{N}=202$ styles $)$. Additional details about style

274 collection and lab procedures are available in Appendix S2.

275

\section{Additional response variables (Heliconia removal experiment only)}

In addition to the primary response variables described above, we examined several other metrics for the Heliconia removal experiment: (1) recapture probability (i.e., proportion of birds captured during the 'pre' period and recaptured during the 'post' period), (2) floral visitation rates from individual birds marked with nail polish, and (3) hummingbird body mass. The first two response variables assessed the possibility that hummingbirds caught during the initial capture sessions were rapidly replaced by new individuals, potentially obscuring treatment effects. To explore whether birds that remained in (or returned to) treatment focal areas were paying an energetic cost, we also analyzed changes in the body mass of hummingbirds captured during both experimental periods. To compare body mass change across hummingbirds of different structural sizes, we calculated body mass relative to the mass predicted by speciesspecific allometric equations (i.e., $\ln$ (body mass) $\ln ($ wing length), Appendix S2: Fig. S4). 


\section{Quantifying connectivity}

Within each focal landscape, we used Google Earth Pro to digitize closed-canopy forest

$$
\mathrm{W}_{j}=\exp \left(-\alpha d_{i j}\right)
$$

where $\alpha$ is the decay rate parameter that scales the effect of distance and $d$ is the shortest

cumulative distance between the focal area centroid $i$ and each forested pixel $j$, staying within the

$$
\mathrm{S}_{i}=\Sigma \mathrm{W}_{j} A_{j}
$$

(Eq. 2)

307 where $\mathrm{W} j$ is the weight of each forested pixel and $A$ is the area of each forested pixel. Geospatial 308 processing was conducted using Google Earth Engine through the JavaScript API (Gorelick et al. 2017). 


\section{Quantifying resource availability}

From the floral resource surveys (see 'Study design'), we estimated the energetic value of

312 the Heliconia flowers and the remaining non-Heliconia resources. Briefly, we converted

313 resource counts (i.e., number flowers and inflorescences) into calories, the most biologically

314 relevant unit for hummingbird energetics (e.g., Wolf, Hainsworth, and Stiles 1972; Stiles 1975).

315 To calculate calories, we measured nectar volume and concentration from $>1400$ flowers $(N=38$

316 species) growing in the focal landscape and/or the Wilson Botanical Garden at the Las Cruces

317 Biological Station, supplementing these measurements with literature data when necessary. We

318 then converted average nectar volume and concentration per flower to calories per plant (see

319 Appendix S2 for full details). Because tropical hummingbirds generally interact with subsets of

320 the available floral resources (e.g., Stiles 1985; Maglianesi et al. 2014; Vizentin-Bugoni,

321 Maruyama, and Sazima 2014), we then generated estimates of caloric availability specific to

322 each hummingbird group examined. These estimates were developed prior to any analysis based

323 on relative visitation rates of each hummingbird species to 37 flowering plant species (Fig. 3).

324 We divided these calorie estimates by focal area size, then natural log-transformed the resulting

325 densities. Floral corolla length was measured from flowers collected in the field, supplemented

326 with literature values when necessary (Appendix S2: Table S16).

\section{Statistical analysis}

We used linear mixed models (LMMs) and generalized linear mixed models (GLMMs) to

329 analyze how experimental Heliconia extinction and natural variation in Heliconia density

330 influenced our primary response variables: (i) captured hummingbird abundance, (ii) proportion

331 of time spent in focal area, (iii) visitation rates to flowering plants (Heliconia and non-

332 Heliconia), and (iv) plant pollination success. Analyses of the Heliconia removal experiment 
333 also included several additional, individual-level response variables (see 'Additional response

334 variables'). To determine whether declines in Heliconia affected Heliconia specialists more

335 strongly than other hummingbird species $(\mathbf{H 4})$, we analyzed all hummingbird responses with (i)

336 the full dataset containing all species, and (ii) a dataset including green hermits and violet

337 sabrewings.

343 inflation, and linearity by visually inspecting residual plots from 'DHARMa' (Hartig 2020).

344 Estimated marginal means were calculated using 'emmeans' (Lenth 2020) and visualized using

345 the 'ggemmeans' function within 'ggeffects' (Lüdecke 2018). Results were considered

346 statistically significant if $P<0.05$.

\section{Heliconia removal experiment}

In a BACI experimental design, an overall treatment effect is indicated by a statistically

350 significant interaction between the variables representing treatment and experimental period

351 (Underwood 1994; McDonald, Erickson, and McDonald 2000). We adopted this standard

352 analytical approach rather than calculating change scores (e.g., pre-post differences) because

353 change scores are nearly always negatively correlated with baseline measurements; when

354 baseline measurements also covary with predictor variables of interest, misleading (i.e.,

355 spuriously negative) relationships can emerge (Allison 1990). Therefore, we tested the parallel 
extinction hypothesis $(\mathbf{H 1 a})$ and robust network hypothesis (H1b) using a two-way interaction

359 included a random intercept for 'Site'. Except when modeling recapture probability, we also

360 included a nested random effect for 'Replicate ID' (Site-Year), which paired pre-post

361 observations within each replicate. Additional nested random effects, namely for plant species

362 and individual birds, were included where applicable (Appendix S2: Table S17). Because we

363 were interested in pre-post changes in our response variables, we only included covariates that

364 varied between pre and post periods. For example, when analyzing hummingbird visitation rates,

365 we accounted for the attractiveness of a given focal plant by including a covariate for the number

366 of open flowers per day, averaged across the experimental period. Since the magnitude of our

367 experimental Heliconia extinction varied widely (see 'Results'), we ran parallel models using a

368 categorical treatment variable (Control/Treatment) and a quantitative treatment variable

369 (Calories removed/hectare). Because results were qualitatively similar, only results from the

370 categorical approach are presented in the main text.

371

372 Natural variation in Heliconia density

373 To complement the Heliconia removal experiment, we also examined hummingbird

374 responses over a natural gradient in Heliconia availability using data from the pre period of the

375 experimental sites. This 'space-for-time' approach elucidates how hummingbird space use and

376 foraging behavior respond to natural variation present in the study area - presumably emerging

377 over longer time scales than those of our removal experiment. We also used this approach to test

378 the connectivity hypothesis and resource hypothesis by modeling the interaction term between 
Heliconia density and either connectivity $(\mathbf{H 2})$ or non-Heliconia resource availability (H3).

380

These hypotheses were not tested using the experimental framework due to limited sample size (and thus statistical power) to enable estimation of a three-way interaction between treatment, experimental period, and resources/connectivity. Because resource availability data were not collected in 2016 control replicates, these replicates $(N=6)$ were excluded from this analysis. In these analyses, we included several additional covariates not included in the analyses of the Heliconia removal experiment. First, we used estimates of non-Heliconia resource availability tailored to each hummingbird group being examined. Because resource availability was moderately correlated with connectivity (Pearson's $r=0.57, P=0.002$, Appendix S2: Figure S6), we included both covariates in all models to statistically control for their independent effects. Analyses of radio telemetry data (i.e., proportion of time spent in focal area) included a covariate for the focal area size. When analyzing visitation rates of Heliconia specialists to nonHeliconia resources, we also included plant corolla length as a covariate, since these relatively long-billed hummingbirds (mean bill lengths of 40 and $33 \mathrm{~mm}$ : Borgella, Snow, and Gavin 2001) are expected to select plant species with long corolla tubes (e.g., Maglianesi et al. 2014; Vizentin-Bugoni, Maruyama, and Sazima 2014; Dalsgaard et al. 2021). We included random effects for Site in all models; additional random effects were included where applicable (Appendix S2: Table S18).

\section{RESULTS}

Across all study sites and years, Heliconia density ranged from 3 to 1131 inflorescences per ha (mean \pm SD: $186 \pm 228$, median: 145, Appendix S3: Table S1). The magnitude of our experiment therefore varied widely; we removed between 8 and 526 Heliconia inflorescences per treatment replicate (mean \pm SD: $172 \pm 138$, median: 138, Appendix S3: Table S2). These 
402

403

404

405

406

407

408

409

410

411

412

413

414

415

416

417

418

419

420

421

422

423

424

inflorescences represented, on average, 96\% $( \pm 5.5 \%)$ of the Heliconia inflorescences

encountered during removal (two focal plants remained uncovered and sometimes plant

inaccessibility limited our capacity to cover). Sizes of focal treatment areas ranged from 0.27 to

7.49 ha (mean \pm SD: $1.7 \pm 1.9$, median: 1.25 , Appendix S3: Table S2), depending on the size of

the forest fragment and the navigability of the terrain. We estimate that, on average, the covered

Heliconia plants supplied $42.5 \%( \pm 30.9 \%$, range: $0.9-90.4 \%)$ of the calories available for the

entire hummingbird community $(N=19$ species, Appendix S3: Table S3) and at least 65.5\% ( \pm 31.3\%, range: $2.4-98 \%$ ) of calories for Heliconia specialists (Fig. 2C, Appendix S3: Table S4).

Focal Heliconia plants were visited by hummingbirds $6.4 \pm 5.7$ times per day (range: 0-25,

median: 5), with green hermits visiting most frequently (75\% of 1,065 sightings).

\section{Overall responses to changes in Heliconia density (H1)}

Hummingbird behavior and pollination success were remarkably resistant to experimentally induced Heliconia extinction. Despite the magnitude of Heliconia removal and confirmed use of Heliconia by hummingbirds, we did not detect an overall effect of local

Heliconia removal hummingbird space use, floral visitation rates, or plant pollination success.

However, when examining these response variables across a natural gradient in Heliconia availability (i.e., the space-for-time approach), we found that floral visitation rates and pollination success declined as Heliconia became scarce. We provide detailed evidence for these findings below.

\section{Hummingbird captures \& radio telemetry}

Overall, we did not find that experimental Heliconia removal decreased hummingbird

abundance or the proportion of time that radio-tagged hummingbirds spent in the focal area.

Although we caught $23 \%$ fewer hummingbirds in the 'post' capture session than the 'pre' 
425

426

427

428

429

430

431

432

433

434

435

436

437

438

439

440

441

442

443

444

445

446

447

capture session in treatment replicates (95\% CI: $-41 \%$ to $1 \%$ ), this pre-post decline fell within the variability of the control replicates (all species: $z=-1.11, P=0.27$; Heliconia specialists: $z=-$

0.5, $P=0.62$; Fig. 4: A-B; Appendix S3: Table S5). Similarly, although radio-tagged

hummingbirds spent $25-30 \%$ less time in focal areas during the 'post' period, we found no evidence that pre-post changes in space use were linked to our experimental manipulation (95\% CI, treatment: $-56 \%$ to $11 \%$; $95 \% \mathrm{CI}$, control: $-56 \%$ to $28 \%$ ). Results were similar when examining all species together (Fig. 4C) and Heliconia specialists separately (Fig. 4D). We also found no evidence that natural variation in Heliconia density influenced the hummingbird space use, quantified either with mist net captures or radio telemetry (Appendix S3: Tables S5-S6).

When examining individual-level hummingbird responses, we also did not detect changes associated with Heliconia removal. On average, the estimated probability of recapturing a hummingbird from the 'pre' capture session was $18 \%$ in control replicates (95\% CI: $11 \%$ to 29 $\%$ ), compared to $14 \%$ in treatment replicates (95\% CI: $97 \%$ to $23 \%$ ). This difference was not statistically significant, and recaptures of Heliconia specialists showed qualitatively similar results (Appendix S3: Fig. S1: A-B, Table S7). Among the individual hummingbirds caught during both sessions, we also found no evidence that pre-post changes in the relative body mass differed between control and treatment replicates (Appendix S3: Table S8).

\section{Floral visitation rates \& pollination success}

Using trail cameras, we continuously monitored hummingbird visitation at the two focal Heliconia inflorescences that remained uncovered throughout the experimental period, as well as numerous other flowering plants (mean \pm SD: $9.3 \pm 2$ species/replicate; range: $6-14)$. Under the robust network hypothesis, we expected hummingbirds to rewire and increasingly use alternative (non-Heliconia) resources. However, we did not find that pre-post changes in hummingbird 
visitation rate differed between control and treatment replicates, either when examining the focal

Heliconia plants $(z=0.83, P=0.41$, Fig. 5: A-B, Appendix S3: Table S9) or non-Heliconia plant species $(z=-0.69, P=0.49$, Fig. 6: A-B, Appendix S3: Table S10). Responses by Heliconia

451 specialists mirrored the responses observed for all species, although these species visited non-

452 Heliconia species relatively infrequently (<1 visit/day, on average: Fig. 6B). Results were similar

453 when examining pre-post changes in visitation rates for individual color-marked hummingbirds

454 observed on camera (Appendix S3: Fig. S1: C-F, Tables S11-S12).

In contrast to the experimental results, we found that natural variation in Heliconia

456 availability strongly influenced visitation to focal Heliconia plants (Fig. 5: D-E). For every

457 standard deviation decrease in the caloric density of Heliconia, we found that overall Heliconia

458 visitation rates decreased by $49 \%$ (95\% CI: $15 \%$ to $93 \%, z=3.03, P=0.0024$, Appendix S3:

459 Table S9). Visitation to non-Heliconia plants also declined when natural Heliconia availability

460 was low, but only for Heliconia specialists $(\mathrm{z}=2.02, P=0.044$, Fig. 6E, Appendix S3: Table

461 S10).

We found no evidence that experimental Heliconia removal influenced pollination

463 success for the focal Heliconia plants $(z=0.23, P=0.82$, Fig. 5C, Appendix S3: Table S13) or

464 another plant species from the floral arrays (Hamelia patens: $z=0.19, P=0.85$, Appendix S3:

465 Table S13). However, when Heliconia availability was naturally low, we observed declines in

466 the pollination success of the focal Heliconia plants; for every standard deviation decrease in the

467 caloric density of Heliconia, the odds of pollination declined by 2.4 times (95\% CI: 1.1 times to

$468 \quad 5.4$ times, $z=2.2, P=0.028$, Fig. 5F). 


\section{Effects of connectivity (H2) and resource availability $(\mathrm{H} 3)$}

470 Hummingbird captures \& radio telemetry

$4726 \%$ for every one-unit increase in connectivity $(95 \% \mathrm{CI}:+1 \%$ to $+12 \%, z=2.31, P=0.021$,

473 Appendix S3: Table S5). Further, radio-tagged birds spent more time in focal areas when

474 alternative (non-Heliconia) resources were abundant; the odds of being in the focal area

475 increased by 2.3 times (95\% CI: 1.3 to 4.1 times) for every standard deviation increase in caloric

476 density (all species only: $z=2.78, P=0.0055$, Appendix S3: Table S6). However, neither

477 connectivity or resource availability appeared to influence hummingbird responses to Heliconia

478 declines, either with experimental removal or across the natural density gradient $(P>0.05$ for all

479 interactions of interest, Appendix S3: Tables S5-S6).

Floral visitation rates \& pollination success

We did not observe any statistically significant main effects of connectivity on

484 specialists declined more sharply when connectivity was low $(z=-1.76, P=0.08$, Appendix S3:

485 Fig. S2, Table S9). This potential connectivity effect did not emerge when examining Heliconia 486 pollination success $(z=-0.55, P=0.58)$. Although we expected that interaction rewiring might

487 be more likely to occur when alternative resources were abundant, we did not find that Heliconia 488 declines in otherwise resource-rich areas caused hummingbirds to rely increasingly on non-

489 Heliconia species (Appendix S3: Table S10).

\section{DISCUSSION}

In this study, we experimentally induced the local extinction of a locally abundant tropical plant, Heliconia tortuosa, to assess the robustness of plant-hummingbird interaction 
networks in a fragmented tropical landscape. Additionally, across a natural gradient in Heliconia density, we assessed whether low Heliconia abundance would lead to parallel declines in hummingbirds and their pollination services - and whether landscape context (connectivity) and local context (alternative resource availability) could buffer against potential declines. Based on suite of complementary response variables we found that, even when very high proportions of total available calories were experimentally removed ( 43-66\% on average), hummingbird responses fell within the natural variability of control replicates. As might be expected with such small changes in hummingbird behavior, we did not observe any cascading effects of experimental manipulation on pollination success of flowering plants, which supports the robust network hypothesis (Hlb). On the other hand, when examining hummingbird responses and

503 pollination success across a natural gradient in Heliconia density, we found evidence for the parallel extinction hypothesis (H1a). In sites where Heliconia density was low, hummingbirds

505 visited individual Heliconia plants less frequently, and these plants experienced reduced pollination success. Other flowering plants also exhibited lower visitation rates from Heliconiaassociated hummingbirds, suggesting that high Heliconia densities may attract these

508 hummingbirds (and/or incentivize repeat visitation) and therefore facilitate pollination for other 509 species.

512 Bunbury et al. 2010) and several other experiments that removed plant species from mutualistic 513 networks (Ferrero et al. 2013; Goldstein and Zych 2016; Costa et al. 2018). However, if

514 hummingbirds remained in forest fragments despite Heliconia declines, we assumed that they 515 would rewire to use alternative floral resources; hummingbirds as a taxonomic group are highly 
opportunistic foragers (Arizmendi and Ornelas 1990; Maruyama et al. 2013) and the most frequent Heliconia visitor, the green hermit, has a relatively wide niche breadth (Fig. 3, see also Borgella, Snow, and Gavin 2001; Betts, Hadley, and Kress 2015). Unexpectedly, we found no evidence that hummingbirds increasingly visited non-Heliconia resources when Heliconia became less available, suggesting that the mechanisms underlying network robustness in this

521 study may not necessarily align with the rewiring observed in previous empirical tests (e.g.,

522 Timóteo et al. 2016; Kaiser-Bunbury et al. 2017; Costa et al. 2018). This apparent lack of

523 foraging flexibility may emerge from various constraints, such as morphological trait-matching,

524 search costs, and/or competition from other hummingbirds (see also Weinstein and Graham

525 2017). For example, high levels of exploitative competition for non-defendable resources may

526 have discouraged hummingbirds from modifying their trapline and risking overlap with another

527 bird's foraging route (Young 1971; Gill 1988; Ohashi and Thomson 2009). Lastly, is possible

528 that fine-scale rewiring did occur but was not detected using our analytical approach, which

529 aggregated visitation rates to the level of hummingbird species; further analysis examining the

530 diversity of pollen grains carried by individual hummingbirds may shed light on the possibility

531 of rewiring at finer scales.

In the absence of rewiring, the resilience in hummingbird behavior, abundance, and

533 pollination services following experimental Heliconia removal is surprising. Brief pauses in 534 nectar intake can disrupt a hummingbird's daily energy balance, given their high metabolic rate 535 and limited energy reserves (Calder and Booser 1973; Tooze and Gass 1985; Brice 1992).

536 Moreover, previous nectar manipulations with hummingbirds - albeit within defended territories

537 - led to rapid changes in territory size, foraging patterns, and/or defense behavior, generally

538 within a day (e.g., Hixon, Carpenter, and Paton 1983; Gass and Sutherland 1985; Eberhard and 
539 Ewald 1994; Temeles et al. 2004). One explanation for our result is that hummingbirds

540 permanently emigrated from fragments after Heliconia removal but, because of high intruder

541 pressure, were quickly replaced by new individuals (Stiles and Wolf 1970). However, we

542 monitored individual birds using several different approaches (radio telemetry, recaptures,

543 visitation rates) and found no evidence that Heliconia removal caused emigration and subsequent

544 replacement. An alternative possibility is that hummingbirds relied on physiological adaptations,

545 such as a torpor and/or insectivory, to maintain body condition despite large declines in nectar

546 availability - resulting in the stable body mass measurements we observed in recaptured

547 hummingbirds. Torpor is an energy-saving adaptation characterized by declines in body

548 temperature and metabolic rate (Hainsworth, Collins, and Wolf 1977; Spence and Tingley 2021),

549 and even tropical hummingbirds inhabiting low-to-mid elevations appear to possess this

550 capability, including the green hermit (Krüger, Prinzinger, and Schuchmann 1982; Bech et al.

551 1997; Shankar et al. 2020; Schuchmann and Prinzinger 1988). Additionally, hummingbirds are

552 highly insectivorous and, although they cannot completely replace nectar with insects (Brice

553 1992; Stiles 1995), they may supplement their diet with arthropods when nectar becomes scarce

554 (Young 1971; Kuban and Neill 1980; Montgomerie and Redsell 1980; Hazlehurst and Karubian

555 2018). Finding torpid hummingbirds at night is extremely challenging (Carpenter and Hixon

556 1988), but future research could explore changes in arthropod consumption using techniques

557 such as DNA metabarcoding (Moran, Prosser, and Moran 2019).

Another explanation for hummingbird persistence following experimental Heliconia

559 removal involves their high movement ability. H. tortuosa is a patchily distributed species that

560 necessitates long-distance foraging movements, as a single clump does not make territoriality

561 energetically profitable (Stiles 1975). Densities can also vary substantially across short distances; 
562 for example, Stiles (1979) notes that some Costa Rican Heliconia species can be common in one

563 watershed, yet nearly absent in an adjacent watershed $<1 \mathrm{~km}$ away (see also Bruna and Kress

564 2002). The most frequent Heliconia visitor, the green hermit, is therefore capable of traveling

565 long distances $(>500 \mathrm{~m})$ while foraging within home ranges of $>150$ ha, although home range

566 sizes of $\sim 2$ ha are more typical (Volpe et al. 2014; 2016). Thus, returning to our focal areas

567 (typically $\sim 1.5$ ha) to visit the few remaining Heliconia resources could be perceived as a

568 relatively low-cost option for long-distance trapliners, at least in the short term. Notably,

569 although highly mobile pollinators might buffer against network collapse (Volpe et al. 2016),

570 they may be vulnerable to habitat loss and fragmentation once thresholds are crossed, leading to

571 parallel pollinator declines observed in nature (Andrén 1994; Hadley and Betts 2012). This

572 strategy is also unlikely to be profitable over longer time scales than measured by our

573 experiment, which only removed Heliconia for five days.

574 The relatively short length of our removal experiment might also explain why - when

575 examining hummingbird responses across a natural gradient in Heliconia availability - lower

576 Heliconia densities were indeed associated with reduced floral visitation rates. Although a short

577 adjustment period ( $<1$ day) is standard in similar species removal experiments (e.g., Hixon,

578 Carpenter, and Paton 1983; Brosi and Briggs 2013; Hazlehurst and Karubian 2018), extending

579 the experimental timeline may have more realistically simulated a future extinction and provided

580 more time for behavioral or demographic adjustment. If hummingbirds were not permanent

581 residents of our focal areas - as suggested by our relatively low recapture rates $(\sim 15 \%)$ and

582 proportion of time spent in the focal area $(\sim 20 \%)$ - then transient individuals might have not

583 immediately noticed changes in Heliconia density and changed their foraging patterns

584 accordingly. Likewise, hummingbirds might not have persisted had we removed Heliconia over 
585 larger areas, because traveling to isolated plants would become even more energetically costly

586 (Heinrich and Raven 1972). Unfortunately, covering (and then uncovering) Heliconia plants in

587 steep terrain with dense understories limited the area we could manipulate.

588 We also acknowledge that our ability to detect experimental effects may have been

589 limited by low statistical power, owing to high individual-level variation and limited sample size.

590 Low statistical power may have also weakened our tests of the connectivity hypothesis and

591 resource hypothesis, as those datasets only included a subset of the replicates included in the

592 experimental analyses (resource availability data were not available for all sites). Still, we

593 emphasize that the spatial scale of our experiment and amount of replication surpasses most

594 other empirical studies simulating species extinctions within plant-pollinator networks

595 (Appendix S1: Table S1). Nevertheless, future removal experiments with highly mobile

596 pollinators should consider increasing the amount of replication, and, if possible, manipulate

597 larger areas.

In the space-for-time component of our study, we found that visitation rates to individual

599 plants decreased with natural declines in Heliconia density, suggesting that Heliconia and its

600 pollinators might facilitate pollination of co-flowering plants in this study system. Indeed,

601 facilitative effects arising from the overall attractiveness of the floral neighborhood are expected

602 to operate most strongly in systems where plants are spatially dispersed and pollinator density is

603 low (Schemske 1981; Ghazoul 2005; Moeller 2004), as is the case in the tropical forest

604 understory. If Heliconia population densities decrease due to habitat fragmentation (Hadley et al.

605 2014), plants visited exclusively by Heliconia-associated hummingbirds might therefore

606 experience a higher risk of reproductive failure (e.g., Pitcairnia imbricata, Calathea

607 guzmanoides, Aphelandra golfodulcensis, Fig. 3). Whether visitation rates map onto pollination 
608

609

610

611

612

613

614

615

616

617

success for these species remains an open question, since pollinator sharing may lead to heterospecific pollen transfer and pollen loss (Ashman and Arceo-Gómez 2013; Morales and Traveset 2008) - tipping the balance toward interspecific competition rather than facilitation (Ghazoul 2005; Mitchell et al. 2009; Rathcke 1983). However, we did discover a positive relationship between visitation rate and pollination success for Heliconia. This relationship has been predicted for other Heliconia species but yielded mixed results (Stein et al. 2013; Bruna et al. 2004), in accordance with accumulating evidence that facilitation effects can be highly context-specific (Bergamo et al. 2020). Nevertheless, this finding suggests that any reproductive declines of Heliconia in this study system might accelerate once extinction debt is realized and conspecific density begins to decline.

\section{CONCLUSIONS}

Although pollinators seemed able to persist during our experiments that removed floral resources for a short period of time (several days), this persistence may not be sustainable or reflect the outcome of a natural extinction process. Indeed, we observed declines in hummingbird visitation when Heliconia availability was naturally low; this reduced hummingbird visitation had cascading consequences for pollination success. Thus, longer-term experiments could be key for predicting consequences of species loss and understanding mechanisms of network robustness - at least for pollinator species that forage at large spatial scales. Our study also suggests that, over the short term, behavioral flexibility to use alternative floral resources might be limited, even in taxonomic groups thought to be highly opportunistic foragers. Thus, even rewiring rules with strong biological underpinnings (e.g., Vizentin-Bugoni et al. 2020) may not necessarily predict real-world responses to species loss, perhaps due to additional constraints such as competition. To further understand the mechanisms underlying 
network robustness or collapse, we encourage future experiments that consider how temporal scale, species traits (e.g., movement ability), competition, and landscape context interact to determine the outcome of species extinctions. These experiments could be especially valuable at geographic range limits, where climate change will likely lead to species replacements (HilleRisLambers et al. 2013), and in the tropics where landscape change and species loss are most rapid (Hansen et al. 2013).

\section{ACKNOWLEDGMENTS}

This material is based upon work supported by the National Science Foundation (NSF) Graduate Research Fellowship Program under Grant No. 1840998 to KGL. Funding for the experiment was provided primarily by NSF-DEB-1457837 to MGB and ASH, with additional grants to KGL from the American Ornithological Society and Sigma Xi. We also thank the Las Cruces Biological Station and the private landowners who allowed us to work on their property. Field assistance was provided by Jorge Araya Paniagua, Michael Atencio Picado, Marion Donald, Dustin Gannon, Jessica Greer, Matt Hadley, Urs Kormann, Daniel Moreno, Mauricio Paniagua Castro, Ignacio Ruiz Ilama, Esteban Sandi Paniagua, Andrés Solorzano Vargas, Laura Sutcliffe, and Felipe Torres Vanegas. Videos from trail cameras were reviewed with the help of Marion

\section{Donald, Colleen Franklin, Jessica Greer, Zoe Griffith, Elena Hart, Billy Hilgert, Zachary} Kendall, Jeremy Lee, Ana Medina Roman, Briley Mullin, Amber Newell, Thanh Nguyen, Zoe Sallada, Allison Simoni, Claire Woods, and Mel Xiao. Nozomi Birkett and Marion Donald helped collect nectar measurements, and Chandler Spruill assisted with pollen tube processing. Ariel Muldoon provided valuable statistical advice, and Mark Novak provided feedback on an earlier version of the manuscript. Response variable icons were created from the following Noun Project images: Hummingbird by Agne Alesiute, net by Guillaume Kurkdjian, Stopwatch by 
654 Thomas Marijinissen, leaves by Tatiana, Camera by Stanislav Levin, and Microscope by Gregor 655 Cresnar.

656

657

658

659

660

661

662

663

664

665

666

667

668

669

670

671

672

673

674

\section{LITERATURE CITED}

Aguilar, R., L. Ashworth, L. Galetto, and M.A. Aizen. 2006. "Plant Reproductive Susceptibility to Habitat Fragmentation: Review and Synthesis through a Meta-Analysis.” Ecology Letters 9 (8): 968-80.

Aizen, M.A., M. Sabatino, and J.M. Tylianakis. 2012. "Specialization and Rarity Predict Nonrandom Loss of Interactions from Mutualist Networks.” Science 335 (6075): 148689.

Allen-Wardell, G., P. Bernhardt, R. Bitner, A. Burquez, S. Buchmann, J. Cane, P.A. Cox, et al. 1998. "The Potential Consequences of Pollinator Declines on the Conservation of Biodiversity and Stability of Food Crop Yields.” Conservation Biology 12 (1): 8-17.

Allison, P.D. 1990. "Change Scores as Dependent Variables in Regression Analysis.” Sociological Methodology 20: 93-114.

Anderson, S.H., D. Kelly, J.J. Ladley, S. Molloy, and J. Terry. 2011. “Cascading Effects of Bird Functional Extinction Reduce Pollination and Plant Density.” Science 331 (6020): 106871.

Andrén, H. 1994. "Effects of Habitat Fragmentation on Birds and Mammals in Landscapes with Different Proportions of Suitable Habitat: A Review.” Oikos 71 (3): 355-66.

Arizmendi, M.C., and J.F. Ornelas. 1990. "Hummingbirds and Their Floral Resources in a Tropical Dry Forest in Mexico.” Biotropica 22 (2): 172-80. 
675

676

677

678

679

680

681

682

683

684

685

686

687

688

689

690

691

692

693

694

695

696

Ashman, T.L., and G. Arceo-Gómez. 2013. "Toward a Predictive Understanding of the Fitness Costs of Heterospecific Pollen Receipt and Its Importance in Co-Flowering Communities." American Journal of Botany 100 (6): 1061-70.

Ashman, T.L., T.M. Knight, J.A. Steets, P. Amarasekare, M. Burd, D.R. Campbell, M.R. Dudash, M.O. Johnston, S.J. Mazer, and R.J. Mitchell. 2004. "Pollen Limitation of Plant Reproduction: Ecological and Evolutionary Causes and Consequences.” Ecology 85 (9): $2408-21$.

Aslan, C.E., E.S. Zavaleta, B. Tershy, and D. Croll. 2013. "Mutualism Disruption Threatens Global Plant Biodiversity: A Systematic Review.” PLOS ONE 8 (6): e66993.

Bascompte, J., and P. Jordano. 2007. "Plant-Animal Mutualistic Networks: The Architecture of Biodiversity." Annual Review of Ecology, Evolution, and Systematics 38 (1): 567-93.

Bascompte, J., P. Jordano, C.J. Melián, and J.M. Olesen. 2003. “The Nested Assembly of PlantAnimal Mutualistic Networks.” Proceedings of the National Academy of Sciences 100 (16): 9383-87.

Bascompte, J., P. Jordano, and J.M. Olesen. 2006. “Asymmetric Coevolutionary Networks Facilitate Biodiversity Maintenance.” Science 312 (5772): 431-33.

Bech, C., A.S. Abe, J.F. Steffensen, M. Berger, and J.E.P.W. Bicudo. 1997. “Torpor in Three Species of Brazilian Hummingbirds under Semi-Natural Conditions.” The Condor 99 (3): $780-88$.

Bergamo, P.J., N.S. Streher, A. Traveset, M. Wolowski, and M. Sazima. 2020. "Pollination Outcomes Reveal Negative Density-Dependence Coupled with Interspecific Facilitation among Plants.” Ecology Letters 23 (1): 129-39. 
Betts, M.G., A.S. Hadley, and W.J. Kress. 2015. "Pollinator Recognition by a Keystone Tropical Plant." Proceedings of the National Academy of Sciences 112 (11): 3433-38.

Biesmeijer, J.C., S.P.M. Roberts, M. Reemer, R. Ohlemüller, M. Edwards, T. Peeters, A.P. Schaffers, et al. 2006. "Parallel Declines in Pollinators and Insect-Pollinated Plants in Britain and the Netherlands." Science 313 (5785): 351-54.

Borgella, R., A.A. Snow, and T.A. Gavin. 2001. "Species Richness and Pollen Loads of Hummingbirds Using Forest Fragments in Southern Costa Rica.” Biotropica 33 (1): 90109.

Brice, A.T. 1992. "The Essentiality of Nectar and Arthropods in the Diet of the Anna's Hummingbird (Calypte Anna)." Comparative Biochemistry and Physiology Part A: Physiology 101 (1): 151-55.

Brooks, M.E., K. Kristensen, K.J. van Benthem, A. Magnusson, C.W. Berg, A. Nielsen, H.J. Skaug, M. Maechler, and B.M. Bolker. 2017. “GlmmTMB Balances Speed and Flexibility Among Packages for Zero-Inflated Generalized Linear Mixed Modeling.” The R Journal 9 (2): 378-400.

Brosi, B.J., and H.M. Briggs. 2013. "Single Pollinator Species Losses Reduce Floral Fidelity and Plant Reproductive Function.” Proceedings of the National Academy of Sciences 110 (32): $13044-48$.

Bruna, E.M., and W.J. Kress. 2002. "Habitat Fragmentation and the Demographic Structure of an Amazonian Understory Herb (Heliconia Acuminata).” Conservation Biology 16 (5): $1256-66$. 
Bruna, E.M., W.J. Kress, F. Marques, and O.F. da Silva. 2004. "Heliconia Acuminata Reproductive Success Is Independent of Local Floral Density.” Acta Amazonica 34 (3): $467-71$.

Calder, W.A., and J. Booser. 1973. "Hypothermia of Broad-Tailed Hummingbirds during Incubation in Nature with Ecological Correlations.” Science 180 (4087): 751-53.

Carpenter, F.L., and M.A. Hixon. 1988. "A New Function for Torpor: Fat Conservation in a Wild Migrant Hummingbird." The Condor 90 (2): 373-78.

Colwell, R.K., R.R. Dunn, and N.C. Harris. 2012. "Coextinction and Persistence of Dependent Species in a Changing World.” Annual Review of Ecology, Evolution, and Systematics 43 (1): 183-203.

Costa, J.M., J.A. Ramos, L.P. da Silva, S. Timóteo, P. Andrade, P.M. Araújo, C. Carneiro, et al. 2018. "Rewiring of Experimentally Disturbed Seed Dispersal Networks Might Lead to Unexpected Network Configurations.” Basic and Applied Ecology 30: 11-22.

Dalsgaard, B., P.K. Maruyama, J. Sonne, K. Hansen, T.B. Zanata, S. Abrahamczyk, R. Alarcón, et al. 2021. "The Influence of Biogeographical and Evolutionary Histories on Morphological Trait-Matching and Resource Specialization in Mutualistic Hummingbird-Plant Networks.” Functional Ecology 35 (5): 1120-33.

Dunn, R.R., N.C. Harris, R.K. Colwell, L.P. Koh, and N.S. Sodhi. 2009. “The Sixth Mass Coextinction: Are Most Endangered Species Parasites and Mutualists?” Proceedings of the Royal Society B: Biological Sciences 276 (1670): 3037-45.

Eberhard, J.R., and P.W. Ewald. 1994. "Food Availability, Intrusion Pressure and Territory Size: An Experimental Study of Anna's Hummingbirds (Calypte Anna).” Behavioral Ecology and Sociobiology 34 (1): 11-18. 
Farwig, N., D. Bailey, E. Bochud, J.D. Herrmann, E. Kindler, N. Reusser, C. Schüepp, and M.H. Schmidt-Entling. 2009. "Isolation from Forest Reduces Pollination, Seed Predation and Insect Scavenging in Swiss Farmland.” Landscape Ecology 24 (7): 919-27.

Feinsinger, P., and R.K. Colwell. 1978. "Community Organization among Neotropical NectarFeeding Birds.” American Zoologist 18 (4): 779-95.

Ferrero, V., S. Castro, J. Costa, P. Acuña, L. Navarro, and J. Loureiro. 2013. "Effect of Invader Removal: Pollinators Stay but Some Native Plants Miss Their New Friend.” Biological Invasions 15 (10): 2347-58.

Garibaldi, L.A., I. Steffan-Dewenter, C. Kremen, J.M. Morales, R. Bommarco, S.A. Cunningham, L.G. Carvalheiro, N.P. Chacoff, J.H. Dudenhöffer, and S.S. Greenleaf. 2011. "Stability of Pollination Services Decreases with Isolation from Natural Areas despite Honey Bee Visits.” Ecology Letters 14 (10): 1062-72.

Gass, C.L., and G.D. Sutherland. 1985. "Specialization by Territorial Hummingbirds on Experimentally Enriched Patches of Flowers: Energetic Profitability and Learning." Canadian Journal of Zoology 63 (9): 2125-33.

Ghazoul, J. 2005. "Pollen and Seed Dispersal among Dispersed Plants.” Biological Reviews 80 (03): 413-43.

Gilbert, L.E. 1980. "Food Web Organization and Conservation of Neotropical Diversity.” In Conservation Biology: An Evolutionary-Ecological Perspective, edited by M.E. Soulé and B.A. Wilcox, 11-33. Sunderland: Sinauer.

Gill, F.B. 1988. "Trapline Foraging by Hermit Hummingbirds: Competition for an Undefended, Renewable Resource.” Ecology 69 (6): 1933-42. 
771

Goldstein, J., and M. Zych. 2016. "What If We Lose a Hub? Experimental Testing of Pollination Network Resilience to Removal of Keystone Floral Resources.” Arthropod-Plant Interactions 10 (3): 263-71.

Gorelick, N., M. Hancher, M. Dixon, S. Ilyushchenko, D. Thau, and R. Moore. 2017. "Google Earth Engine: Planetary-Scale Geospatial Analysis for Everyone.” Remote Sensing of Environment 202: 18-27.

Hadley, A.S., and M.G. Betts. 2009. "Tropical Deforestation Alters Hummingbird Movement Patterns.” Biology Letters 5 (2): 207-10.

—. 2012. "The Effects of Landscape Fragmentation on Pollination Dynamics: Absence of Evidence Not Evidence of Absence.” Biological Reviews 87 (3): 526-44.

Hadley, A.S., S.J.K. Frey, W.D. Robinson, and M.G. Betts. 2018. "Forest Fragmentation and Loss Reduce Richness, Availability, and Specialization in Tropical Hummingbird Communities." Biotropica 50 (1): 74-83.

Hadley, A.S., S.J.K. Frey, W.D. Robinson, W.J. Kress, and M.G. Betts. 2014. "Tropical Forest Fragmentation Limits Pollination of a Keystone Understory Herb.” Ecology 95 (8): $2202-12$.

Hainsworth, F.R., B.G. Collins, and L.L. Wolf. 1977. "The Function of Torpor in Hummingbirds.” Physiological Zoology 50 (3): 215-22.

Hanski, I. 1994. "Patch-Occupancy Dynamics in Fragmented Landscapes." Trends in Ecology \& Evolution 9 (4): 131-35. . 1998. "Metapopulation Dynamics.” Nature 396 (6706): 41-49.

Hartig, F. 2020. DHARMa: Residual Diagnostics for Hierarchical (Multi-Level / Mixed) Regression Models. https://CRAN.R-project.org/package=DHARMa. 
Hazlehurst, J.A., and J.O. Karubian. 2018. "Impacts of Nectar Robbing on the Foraging Ecology of a Territorial Hummingbird." Behavioural Processes 149: 27-34.

Heinrich, B., and P.H. Raven. 1972. "Energetics and Pollination Ecology.” Science 176 (4035): $597-602$.

HilleRisLambers, J., M.A. Harsch, A.K. Ettinger, K.R. Ford, and E.J. Theobald. 2013. “How Will Biotic Interactions Influence Climate Change-Induced Range Shifts?" Annals of the New York Academy of Sciences 1297 (1): 112-25.

Hixon, M.A., F.L. Carpenter, and D.C. Paton. 1983. “Territory Area, Flower Density, and Time Budgeting in Hummingbirds: An Experimental and Theoretical Analysis.” The American Naturalist 122 (3): 366-91.

Jackson, E.R. 2017. "Does the Matrix Matter? Using Radio Frequency Identification (RFID) Technology to Examine Hummingbird Movements in Fragmented Tropical Landscapes.” Master's thesis, Oregon State University. https://ir.library.oregonstate.edu/concern/graduate_thesis_or_dissertations/cj82kd06n.

Jordán, F. 2009. “Keystone Species and Food Webs.” Philosophical Transactions of the Royal Society B: Biological Sciences 364 (1524): 1733-41.

Kaiser-Bunbury, C.N., J. Mougal, A.E. Whittington, T. Valentin, R. Gabriel, J.M. Olesen, and N. Blüthgen. 2017. "Ecosystem Restoration Strengthens Pollination Network Resilience and Function." Nature 542 (7640): 223-27.

Kaiser-Bunbury, C.N., S. Muff, J. Memmott, C.B. Müller, and A. Caflisch. 2010. "The Robustness of Pollination Networks to the Loss of Species and Interactions: A Quantitative Approach Incorporating Pollinator Behaviour.” Ecology Letters 13 (4): 44252. 
809

810

\section{1}

812

813

814

815

816

817

818

819

820

821

822

823

824

825

826

827

828

829

830

Kearns, C.A., and D.W. Inouye. 1993. Techniques for Pollination Biologists. Niwot: University Press of Colorado.

Kearns, C.A., D.W. Inouye, and N.M. Waser. 1998. "Endangered Mutualisms: The Conservation of Plant-Pollinator Interactions.” Annual Review of Ecology and Systematics 29 (1): 83112.

Klein, A.-M., B.E. Vaissière, J.H. Cane, I. Steffan-Dewenter, S.A. Cunningham, C. Kremen, and T. Tscharntke. 2007. "Importance of Pollinators in Changing Landscapes for World Crops." Proceedings of the Royal Society B: Biological Sciences 274 (1608): 303-13.

Koh, L.P., R.R. Dunn, N.S. Sodhi, R.K. Colwell, H.C. Proctor, and V.S. Smith. 2004. "Species Coextinctions and the Biodiversity Crisis.” Science 305 (5690): 1632-34.

Kormann, U., C. Scherber, T. Tscharntke, N. Klein, M. Larbig, J.J. Valente, A.S. Hadley, and M.G. Betts. 2016. “Corridors Restore Animal-Mediated Pollination in Fragmented Tropical Forest Landscapes.” Proceedings of the Royal Society B: Biological Sciences 283 (1823): 20152347.

Krüger, K., R. Prinzinger, and K.-L. Schuchmann. 1982. “Torpor and Metabolism in Hummingbirds." Comparative Biochemistry and Physiology Part A: Physiology 73 (4): 679-89.

Kuban, J.F., and R.L. Neill. 1980. "Feeding Ecology of Hummingbirds in the Highlands of the Chisos Mountains, Texas.” The Condor 82 (2): 180-85.

Kuussaari, M., R. Bommarco, R.K. Heikkinen, A. Helm, J. Krauss, R. Lindborg, E. Öckinger, et al. 2009. "Extinction Debt: A Challenge for Biodiversity Conservation." Trends in Ecology \& Evolution 24 (10): 564-71. 
Lenth, R. 2020. Emmeans: Estimated Marginal Means, Aka Least-Squares Means. https://CRAN.R-project.org/package=emmeans.

Lüdecke, D. 2018. "Ggeffects: Tidy Data Frames of Marginal Effects from Regression Models." Journal of Open Source Software 3 (26): 772.

Lüdecke, D., M. Ben-Shachar, I. Patil, P. Waggoner, and D. Makowski. 2021. 'Performance: An R Package for Assessment, Comparison and Testing of Statistical Models.” Journal of Open Source Software 6 (60): 3139.

Maglianesi, M.A., N. Blüthgen, K. Böhning-Gaese, and M. Schleuning. 2014. "Morphological Traits Determine Specialization and Resource Use in Plant-Hummingbird Networks in the Neotropics.” Ecology 95 (12): 3325-34.

Maruyama, P.K., G.M. Oliveira, C. Ferreira, B. Dalsgaard, and P.E. Oliveira. 2013. "Pollination Syndromes Ignored: Importance of Non-Ornithophilous Flowers to Neotropical Savanna Hummingbirds.” Naturwissenschaften 100 (11): 1061-68.

McDonald, T.L., W.P. Erickson, and L.L. McDonald. 2000. “Analysis of Count Data from Before-after Control-Impact Studies.” Journal of Agricultural, Biological, and Environmental Statistics 5 (3): 262-79.

Memmott, J., N.M. Waser, and M.V. Price. 2004. “Tolerance of Pollination Networks to Species Extinctions.” Proceedings of the Royal Society of London B: Biological Sciences 271 (1557): 2605-11.

Mendenhall, C.D., and A.M. Wrona. 2018. "Improving Tree Cover Estimates for Fine-Scale Landscape Ecology.” Landscape Ecology 33 (10): 1691-96.

Mitchell, R.J., R.J. Flanagan, B.J. Brown, N.M. Waser, and J.D. Karron. 2009. "New Frontiers in Competition for Pollination." Annals of Botany 103 (9): 1403-13. 
Moeller, D.A. 2004. "Facilitative Interactions among Plants via Shared Pollinators." Ecology 85 (12): 3289-3301.

Moilanen, A., and M. Nieminen. 2002. "Simple Connectivity Measures in Spatial Ecology." Ecology 83 (4): 1131-45.

Montero-Castaño, A., and M. Vilà. 2012. "Impact of Landscape Alteration and Invasions on Pollinators: A Meta-Analysis.” Journal of Ecology 100 (4): 884-93.

Montgomerie, R.D., and C.A. Redsell. 1980. “A Nesting Hummingbird Feeding Solely on Arthropods." The Condor 82 (4): 463.

Morales, C.L., and A. Traveset. 2008. “Interspecific Pollen Transfer: Magnitude, Prevalence and Consequences for Plant Fitness." Critical Reviews in Plant Sciences 27 (4): 221-38.

Moran, A.J., S.W.J. Prosser, and J.A. Moran. 2019. "DNA Metabarcoding Allows Non-Invasive Identification of Arthropod Prey Provisioned to Nestling Rufous Hummingbirds (Selasphorus Rufus).” PeerJ 7: e6596.

Ohashi, K., and J.D. Thomson. 2009. “Trapline Foraging by Pollinators: Its Ontogeny, Economics and Possible Consequences for Plants.” Annals of Botany 103 (9): 1365-78.

Ollerton, J., R. Winfree, and S. Tarrant. 2011. "How Many Flowering Plants Are Pollinated by Animals?" Oikos 120 (3): 321-26.

Pauw, A., and J.A. Hawkins. 2011. "Reconstruction of Historical Pollination Rates Reveals Linked Declines of Pollinators and Plants." Oikos 120 (3): 344-49.

Phillips, R.D., R. Peakall, B.A. Retter, K. Montgomery, M.H.M. Menz, B.J. Davis, C. Hayes, G.R. Brown, N.D. Swarts, and K.W. Dixon. 2015. "Pollinator Rarity as a Threat to a Plant with a Specialized Pollination System.” Botanical Journal of the Linnean Society 179 (3): 511-25. 
877 Potts, S.G., J.C. Biesmeijer, C. Kremen, P. Neumann, O. Schweiger, and W.E. Kunin. 2010.

878

879

880

881

882

883

884

885

886

887

888

889

890

891

892

893

894

895

896

897

898
"Global Pollinator Declines: Trends, Impacts and Drivers.” Trends in Ecology \& Evolution 25 (6): 345-53.

Powers, D.R., A.R. Brown, and J.A. Van Hook. 2003. "Influence of Normal Daytime Fat Deposition on Laboratory Measurements of Torpor Use in Territorial versus Nonterritorial Hummingbirds.” Physiological and Biochemical Zoology 76 (3): 389-97.

R Core Team. 2021. R: A Language and Environment for Statistical Computing. Vienna, Austria: R Foundation for Statistical Computing. https://www.R-project.org/.

Ramos-Jiliberto, R., F.S. Valdovinos, P. Moisset de Espanés, and J.D. Flores. 2012.

“Topological Plasticity Increases Robustness of Mutualistic Networks.” Journal of Animal Ecology 81 (4): 896-904.

Rathcke, B. 1983. “Competition and Facilitation among Plants for Pollination.” In Pollination Biology, edited by L.A. Real, 305-29. New York: Academic Press.

Regan, E.C., L. Santini, L. Ingwall-King, M. Hoffmann, C. Rondinini, A. Symes, J. Taylor, and S.H.M. Butchart. 2015. "Global Trends in the Status of Bird and Mammal Pollinators." Conservation Letters 8 (6): 397-403.

Renjifo, L.M. 2001. "Effect of Natural and Anthropogenic Landscape Matrices on the Abundance of Subandean Bird Species.” Ecological Applications 11 (1): 14-31.

Rodríguez-Flores, C.I., J.F. Ornelas, S. Wethington, and M.C. Arizmendi. 2019. “Are Hummingbirds Generalists or Specialists? Using Network Analysis to Explore the Mechanisms Influencing Their Interaction with Nectar Resources." PLOS ONE 14 (2): $\mathrm{e} 0211855$. 
Russell, S.M., and R.O. Russell. 2001. The North American Banders' Manual for Banding Hummingbirds. North American Banding Council.

Schemske, D.W. 1981. "Floral Convergence and Pollinator Sharing in Two Bee-Pollinated Tropical Herbs.” Ecology 62 (4): 946-54.

Scheper, J., M. Reemer, R. van Kats, W.A. Ozinga, G.T.J. van der Linden, J.H.J. Schaminée, H. Siepel, and D. Kleijn. 2014. “Museum Specimens Reveal Loss of Pollen Host Plants as Key Factor Driving Wild Bee Decline in The Netherlands." Proceedings of the National Academy of Sciences 111 (49): 17552-57.

Schuchmann, K.-L., and R. Prinzinger. 1988. “Energy Metabolism, Nocturnal Torpor, and Respiration Frequency in a Green Hermit (Phaethornis Guy).” Journal Für Ornithologie 129 (4): 469-72.

Senapathi, D., L.G. Carvalheiro, J.C. Biesmeijer, C.-A. Dodson, R.L. Evans, M. McKerchar, R.D. Morton, et al. 2015. “The Impact of over 80 Years of Land Cover Changes on Bee and Wasp Pollinator Communities in England." Proceedings of the Royal Society B: Biological Sciences 282 (1806): 20150294.

Shankar, A., R.J. Schroeder, S.M. Wethington, C.H. Graham, and D.R. Powers. 2020. "Hummingbird Torpor in Context: Duration, More than Temperature, Is the Key to Nighttime Energy Savings.” Journal of Avian Biology 51 (5): e02305.

Spence, A.R., and M.W. Tingley. 2021. "Body Size and Environment Influence Both Intraspecific and Interspecific Variation in Daily Torpor Use across Hummingbirds.” Functional Ecology 35 (4): 870-83.

Steffan-Dewenter, I., and T. Tscharntke. 1999. “Effects of Habitat Isolation on Pollinator Communities and Seed Set.” Oecologia 121 (3): 432-40. 
922 Stein, K., M. Templin, I. Hensen, M. Fischer, D. Matthies, and M. Schleuning. 2013. "Negative

923

924

925

926

927

928

929

930

931

932

933

934

935

936

937

938

939

940

941

942

943

944

Effects of Conspecific Floral Density on Fruit Set of Two Neotropical Understory

Plants." Biotropica 45 (3): 325-32.

Stiles, F.G. 1975. "Ecology, Flowering Phenology, and Hummingbird Pollination of Some Costa Rican Heliconia Species.” Ecology 56 (2): 285-301.

- 1979. "Notes on the Natural History of Heliconia (Musaceae) in Costa Rica. Notas

Sobre La Historia Natural de Heliconia (Musaceae) En Costa Rica.” Brenesia 15: 151-

80.

. 1985. "Seasonal Patterns and Coevolution in the Hummingbird-Flower Community of a Costa Rican Subtropical Forest.” Ornithological Monographs 36: 757-87.

_. 1995. "Intraspecific and Interspecific Variation in Molt Patterns of Some Tropical Hummingbirds." The Auk 112 (1): 118-32.

Stiles, F.G., and L.L. Wolf. 1970. "Hummingbird Territoriality at a Tropical Flowering Tree." The Auk 87 (3): 467-91.

Stratton, D.A. 1989. "Longevity of Individual Flowers in a Costa Rican Cloud Forest: Ecological Correlates and Phylogenetic Constraints.” Biotropica 21 (4): 308-18.

Suarez, R.K. 1992. "Hummingbird Flight: Sustaining the Highest Mass-Specific Metabolic Rates among Vertebrates.” Experientia 48 (6): 565-70.

Taki, H., P.G. Kevan, and J.S. Ascher. 2007. "Landscape Effects of Forest Loss in a Pollination System.” Landscape Ecology 22 (10): 1575-87.

Taylor, J., and S.A. White. 2007. "Observations of Hummingbird Feeding Behavior at Flowers of Heliconia Beckneri and H. Tortuosa in Southern Costa Rica.” Ornitologia Neotropical 18: 133-38. 
945 Taylor, P.D., L. Fahrig, K. Henein, and G. Merriam. 1993. “Connectivity Is a Vital Element of Landscape Structure.” Oikos, 571-73.

947 Temeles, E.J., A.B. Muir, E.B. Slutsky, and M.N. Vitousek. 2004. "Effect of Food Reductions on Territorial Behavior of Purple-Throated Caribs.” The Condor 106 (3): 691-95.

Thomas-Granger, K. 2003. "Light Sum, Nitrogen Level and Growth Retardant Effects on Flower and Nectar Production in Stachytarpheta Frantzii." Master's thesis.

951 Timóteo, S., J.A. Ramos, I.P. Vaughan, and J. Memmott. 2016. "High Resilience of Seed Dispersal Webs Highlighted by the Experimental Removal of the Dominant Disperser.” Current Biology 26 (7): 910-15.

Tooze, Z.J., and C.L. Gass. 1985. "Responses of Rufous Hummingbirds to Midday Fasts.” Canadian Journal of Zoology 63 (10): 2249-53. Scientific Reports 7: 6915.

Underwood, A.J. 1994. “On Beyond BACI: Sampling Designs That Might Reliably Detect Environmental Disturbances.” Ecological Applications 4 (1): 3-15.

Valdovinos, F.S., P. Moisset de Espanés, J.D. Flores, and R. Ramos-Jiliberto. 2013. “Adaptive Foraging Allows the Maintenance of Biodiversity of Pollination Networks.” Oikos 122 (6): $907-17$.

Vellend, M., K. Verheyen, H. Jacquemyn, A. Kolb, H.V. Calster, G. Peterken, and M. Hermy. 2006. "Extinction Debt of Forest Plants Persists for More Than a Century Following Habitat Fragmentation.” Ecology 87 (3): 542-48. 
Vizentin-Bugoni, J., V.J. Debastiani, V.A.G. Bastazini, P.K. Maruyama, and J.H. Sperry. 2020. "Including Rewiring in the Estimation of the Robustness of Mutualistic Networks." Methods in Ecology and Evolution 11 (1): 106-16.

Vizentin-Bugoni, J., P.K. Maruyama, and M. Sazima. 2014. "Processes Entangling Interactions in Communities: Forbidden Links Are More Important than Abundance in a Hummingbird-Plant Network." Proceedings of the Royal Society B: Biological Sciences 281 (1780): 20132397.

Volpe, N.L., A.S. Hadley, W.D. Robinson, and M.G. Betts. 2014. "Functional Connectivity Experiments Reflect Routine Movement Behavior of a Tropical Hummingbird Species.” Ecological Applications 24 (8): 2122-31.

Volpe, N.L., W.D. Robinson, S.J.K. Frey, A.S. Hadley, and M.G. Betts. 2016. "Tropical Forest Fragmentation Limits Movements, but Not Occurrence of a Generalist Pollinator Species.” PLOS ONE 11 (12): e0167513.

Weiner, C.N., M. Werner, K.E. Linsenmair, and N. Blüthgen. 2014. "Land-Use Impacts on Plant-Pollinator Networks: Interaction Strength and Specialization Predict Pollinator Declines." Ecology 95 (2): 466-74.

Weinstein, B.G. 2015. “MotionMeerkat: Integrating Motion Video Detection and Ecological Monitoring." Methods in Ecology and Evolution 6 (3): 357-62.

Weinstein, B.G., and C.H. Graham. 2017. "Persistent Bill and Corolla Matching despite Shifting Temporal Resources in Tropical Hummingbird-Plant Interactions.” Ecology Letters 20 (3): $326-35$.

Winfree, R., I. Bartomeus, and D.P. Cariveau. 2011. "Native Pollinators in Anthropogenic Habitats.” Annual Review of Ecology, Evolution, and Systematics 42 (1): 1-22. 
990 Wolf, L.L., F.R. Hainsworth, and F.G. Stiles. 1972. "Energetics of Foraging: Rate and Efficiency

991 of Nectar Extraction by Hummingbirds.” Science 176 (4041): 1351-52.

992 Wolf, L.L., and F.G. Stiles. 1989. “Adaptations for the 'fail-Safe' Pollination of Specialized

$993 \quad$ Ornithophilous Flowers." The American Midland Naturalist 121 (1): 1-10.

994 Young, A.M. 1971. "Foraging for Insects by a Tropical Hummingbird.” The Condor 73 (1): 36-

$995 \quad 45$.

996 Zahawi, R.A., G. Duran, and U. Kormann. 2015. "Sixty-Seven Years of Land-Use Change in

997 Southern Costa Rica.” PLOS ONE 10 (11): e0143554. 
999 Table 1. Hypotheses testing whether declines of a locally common, tropical flowering plant (Heliconia tortuosa) affect hummingbird space use, hummingbird floral visitation rates, and plant pollination success. Predicted effects are indicated in the column below each

1001 hypothesis. To address Question 1, we (i) experimentally removed H. tortuosa using a BACI (Before-After-Control-Impact)

1002 experimental design and (ii) studied a natural gradient in H. tortuosa density. Under the experimental framework, predicted effects can

1003 be conceptualized as pre-post changes in treatment replicates, compared to to pre-post changes in control replicates. To address

1004 Question 2, we examined changes in hummingbird and plant responses across a natural gradient in $H$. tortuosa density only. 


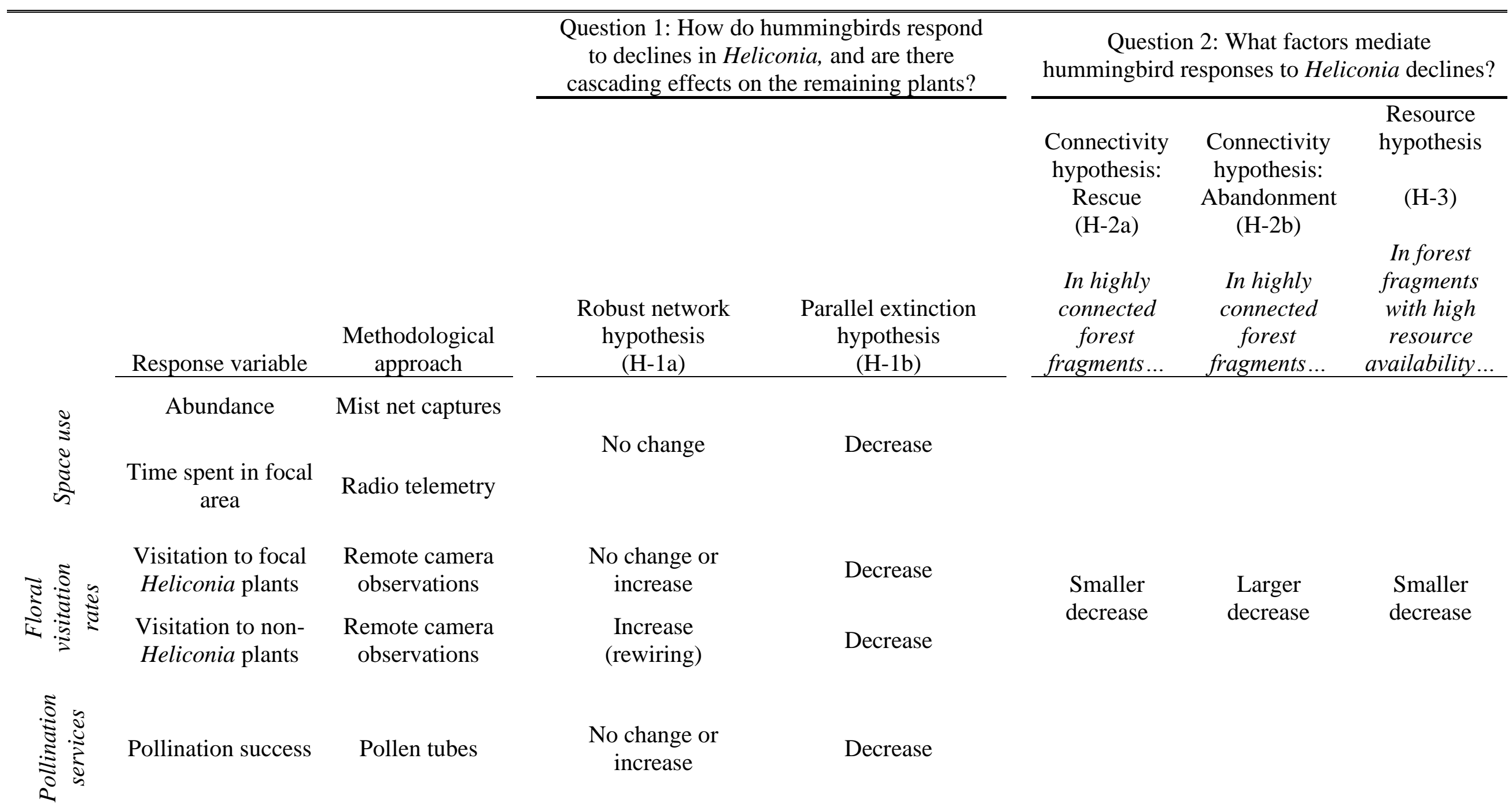


bioRxiv preprint doi: https://doi.org/10.1101/2022.02.24 481682; this version posted February 25, 2022. The copyright holder for this preprint (which was not certified by peer review) is the author/funder, who has granted bioRxiv a license to display the preprint in perpetuity. It is made available under aCC-BY-NC-ND 4.0 International license.

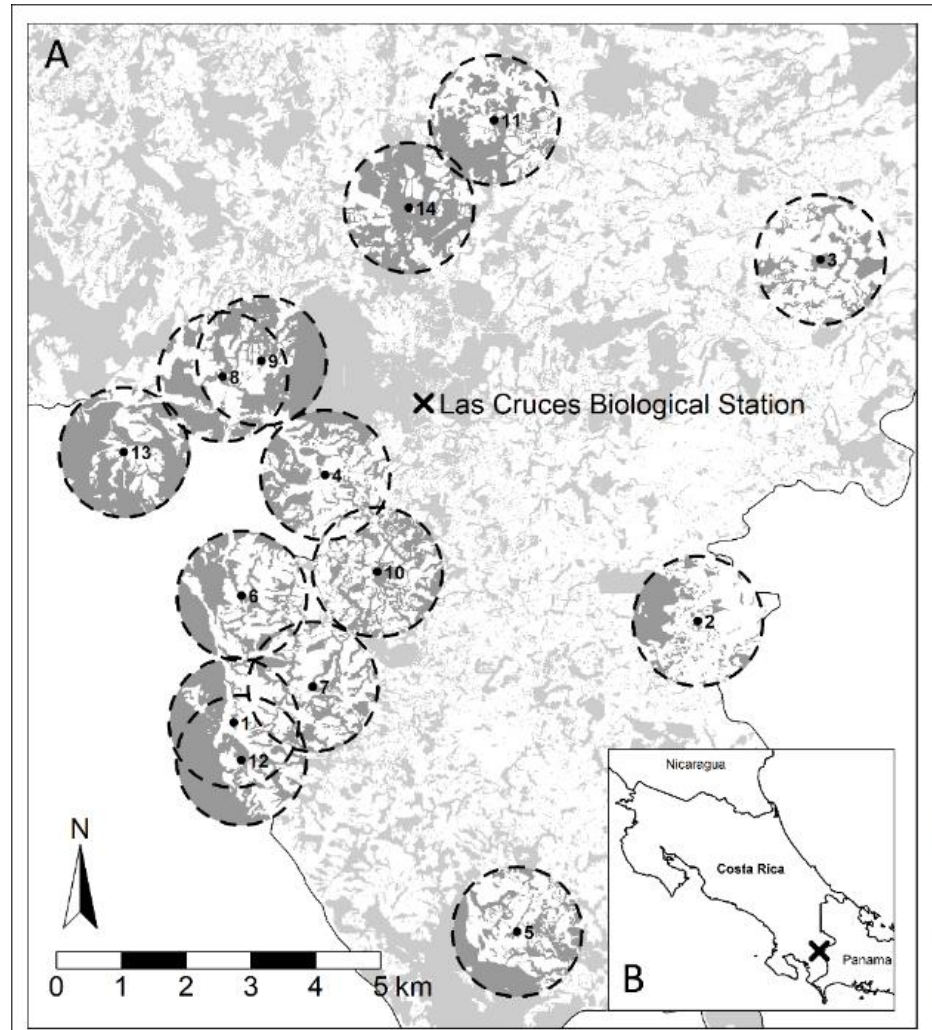

\section{Non-forest \\ Forest}

- Focal fragment

- - Focal landscape

- Focal area

$\Delta$ Mist net

(2) Camera station

- Additional camera

\section{Pixel weight}
0.0
0.2
0.4
0.8
1.0
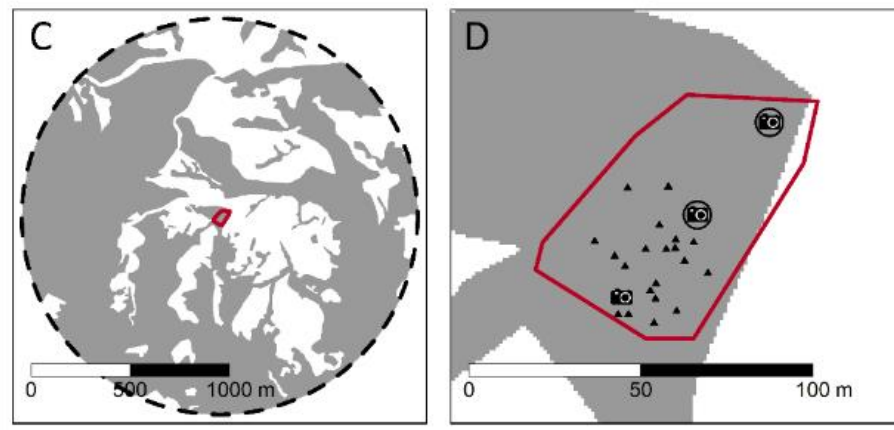
1009 Figure 1. This study was conducted within forest fragments in the landscape surrounding the Las

1010 Cruces Biological Station (A) in southern Costa Rica (B). Map in (A) illustrates forest (grey) and

1011 non-forest (white), with non-forest primarily comprising pasture. The dark grey forest layer was

1012 hand-digitized for this study; the light grey forest layer, available within the geographic

1013 boundary of Coto Brus Canton, was obtained from Mendenhall \& Wrona (2018). We utilized

1014 fourteen focal landscapes of $1000 \mathrm{~m}$ radius ('sites', dashed circles), numbered here by increasing

1015 connectivity to other areas of forest. Most sites were used more than once across three years of

1016 study (2016-2018). Within a year, each site received either the Heliconia removal treatment or

1017 was assigned to be a control. Treatments were reversed in alternate years for a total sample size

1018 of 16 control replicates and 16 treatment replicates. An example site is depicted in (C). Red

1019 outlines in (C) and (D) represent a focal area in which we removed Heliconia (in treatment

1020 replicates) and surveyed floral resources (in all replicates). Within each focal area, we captured

1021 hummingbirds using mist nets (triangles in D) and surveyed plant-hummingbird interactions

1022 using trail cameras (icons in D). To quantify functional connectivity, we summed the total area

1023 of connected forest within the focal landscape, with connectedness based on 50-m gap crossing

1024 ability and pixels down-weighted based on distance to focal area (E; see Appendix S2 for

1025 details). 


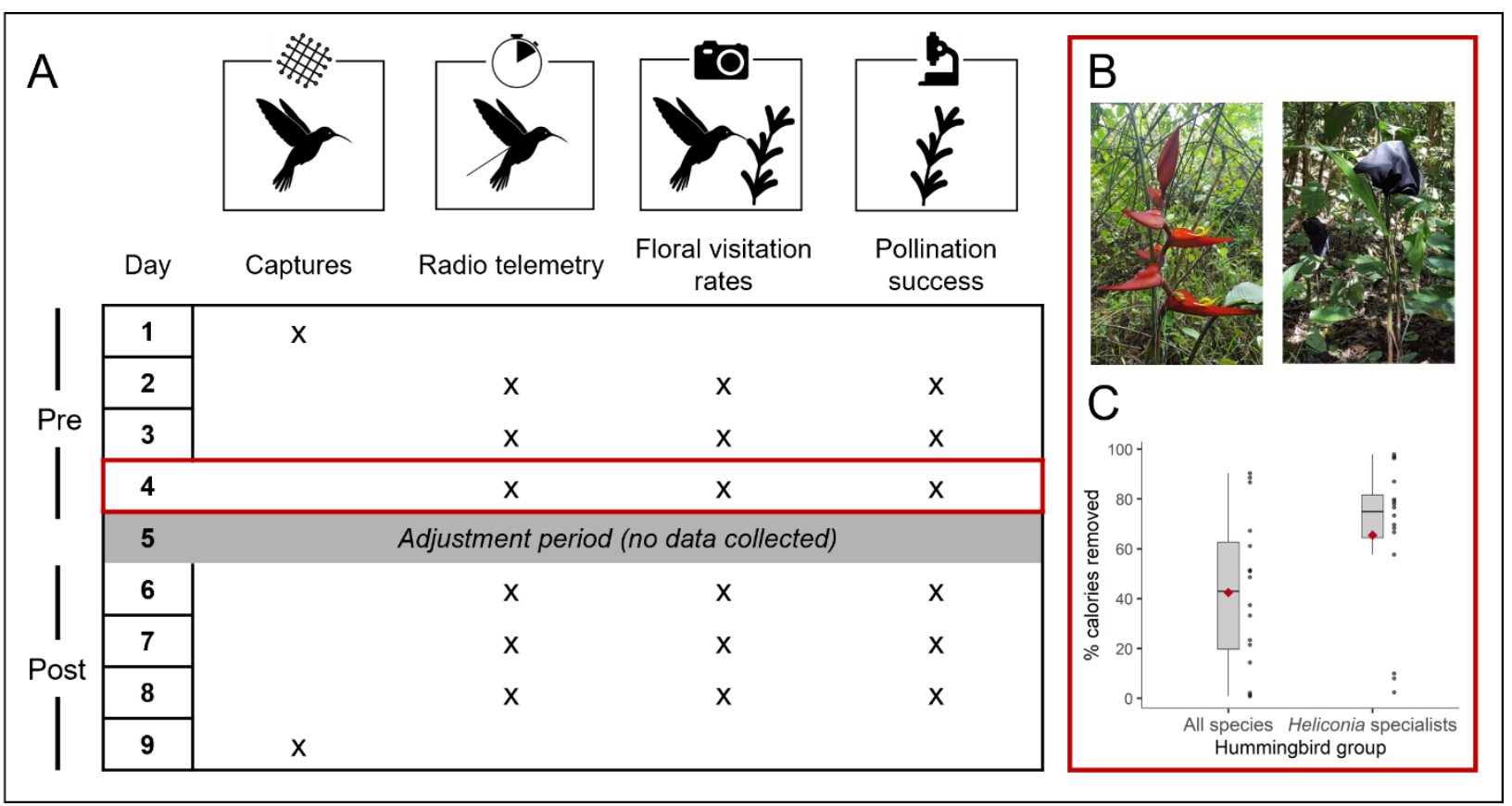

Figure 2. (A) During the Heliconia removal experiment, we measured four main response variables: captured hummingbird abundance, proportion of time radio-tagged hummingbirds spent in the focal area, floral visitation rates, and plant pollination success. Each response variable was measured during both experimental periods (pre and post); the sampling schedule for each is denoted with an ' $\mathrm{X}$ '. Each experimental replicate used two sites (control and treatment) sampled using this schedule, offset by one day. Starting around noon on the fourth day, we covered Heliconia inflorescences in the treatment site. (B) Heliconia inflorescences were covered with dark-colored bags that prevented hummingbirds from accessing any nectar present. (C) Our manipulation removed, on average, $42.5 \%( \pm 30.9 \% \mathrm{SD})$ of the calories available for the entire hummingbird community and $65.5 \%( \pm 31.3 \% \mathrm{SD})$ of the available calories for Heliconia specialists (green hermits and violet sabrewings). Mean values are denoted by red diamonds, and the darker black line represents the median. Lower and upper lines within boxplots represent the first and third quartiles. Whiskers extend from the first and third quartiles to the lowest and highest values within 1.5 times the interquartile range. Individual data points 
bioRxiv preprint doi: https://doi.org/10.1101/2022.02.24.481682; this version posted February 25, 2022. The copyright holder for this preprint

(which was not certified by peer review) is the author/funder, who has granted bioRxiv a license to display the preprint in perpetuity. It is made available under aCC-BY-NC-ND 4.0 International license.

1041 appear next to each boxplot. Response variable icons in (A) were created using images from the

1042 Noun Project (see 'Acknowledgments'). Photos in (B) were provided by Marion Donald. 


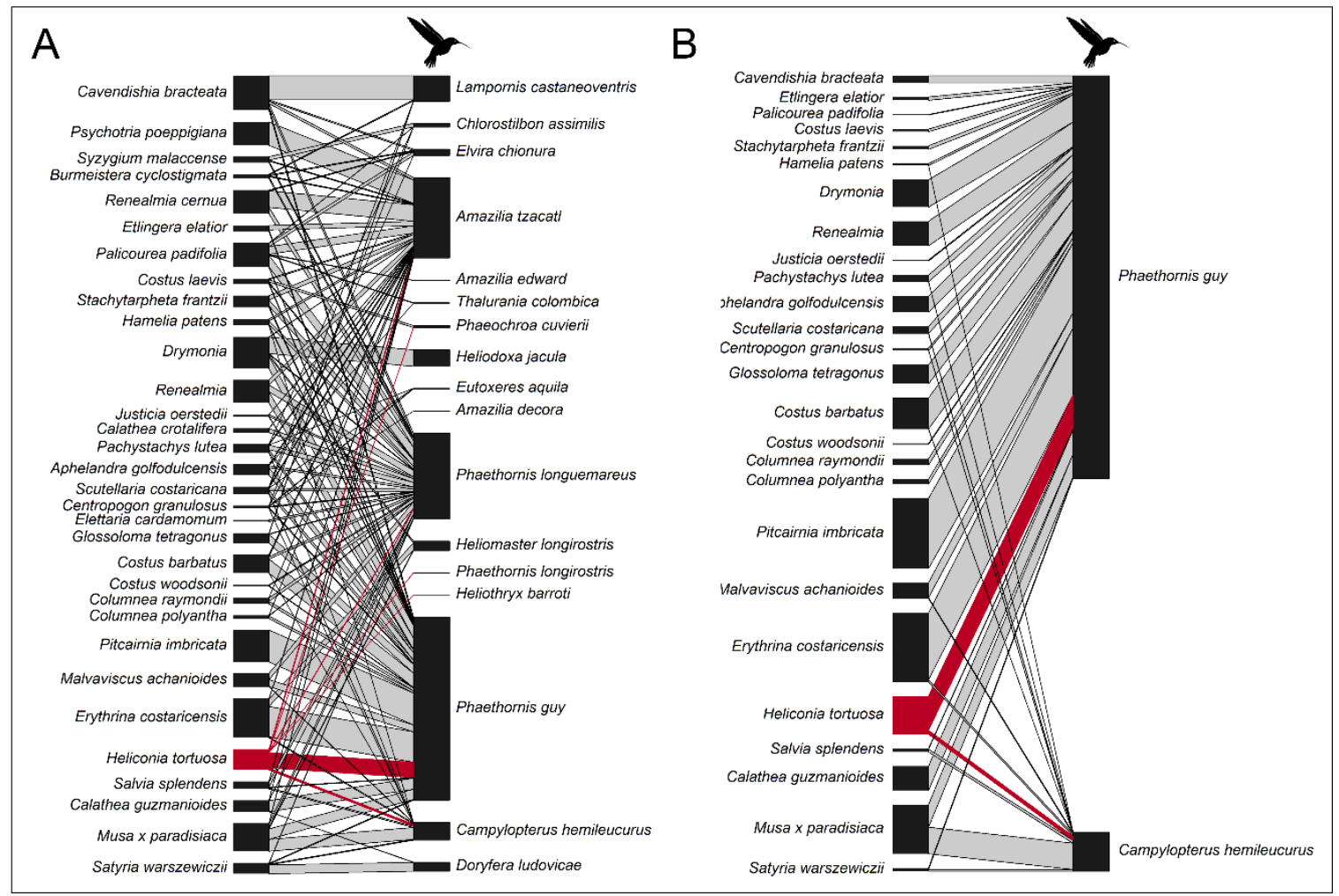

1044 Figure 3. The overall plant-hummingbird visitation network for forest fragments in the

1045 landscape surrounding the Las Cruces Biological Station (A), created from 15,196 hours of

1046 camera observations across 37 plant species, 14 study sites, and three field seasons (2016-2018).

1047 (B) The network in A, but subset to focus on visitation by green hermits (P. guy) and violet

1048 sabrewings ( $C$. hemileucurus), the two most frequent visitors to Heliconia. The height of each

1049 rectangle represents the overall observation frequency for that species (larger rectangle $=$ more

1050 observations), while width of the connecting links reflects relative visitation rate to different

1051 partners (wider link = higher visitation rate). Five plant species (Calathea lutea, Ctenanthe

1052 dasycarpa, Erythrina poeppigiana, Maripa nicaraguensis, Mucuna globulifera) received no

1053 hummingbird visitation during the observation period and are thus not represented in these

1054 networks. 

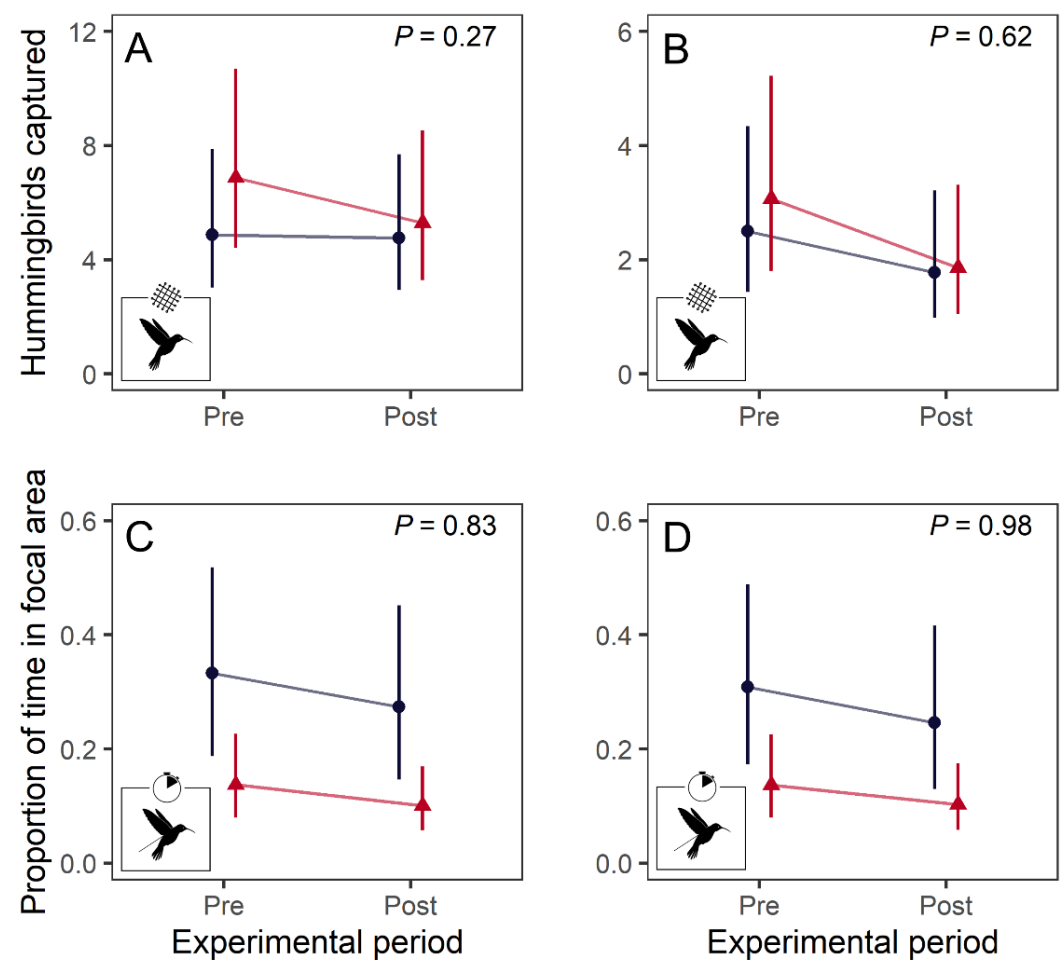

Heliconia removal $\rightarrow$ Control $\rightarrow$ Treatment

1057 understory plant, Heliconia tortuosa, within forest fragments in southern Costa Rica. Despite

1058 removing at least $43 \%( \pm 31 \mathrm{SD})$ of calories available to hummingbirds within focal areas of 1.7

1059 ha ( \pm 1.9 SD), we did not observe an effect of Heliconia removal on the number of

1060 hummingbirds captured (A-B) or the proportion of time that radio-tagged hummingbirds spent in

1061 the focal areas (C-D). Results are shown for all species analyzed (left) and green hermits and

1062 violet sabrewings (right). Estimated marginal means from GLMMs are presented alongside 95\%

1063 confidence intervals. $P$-values refer to the interaction testing the effect of Heliconia removal,

1064 relative to control replicates; conceptually, a treatment effect is indicated by non-parallel lines.

1065 The estimated number of captured hummingbirds is calculated for 45.8 net-hours, the mean

1066 capture effort across all replicates. 


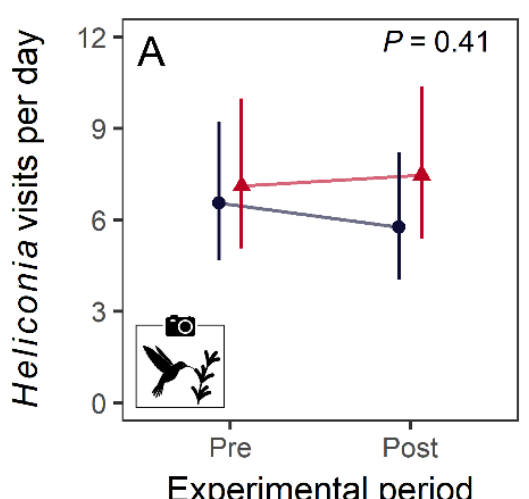

Heliconia removal $\bullet$ Control $\_$Treatment
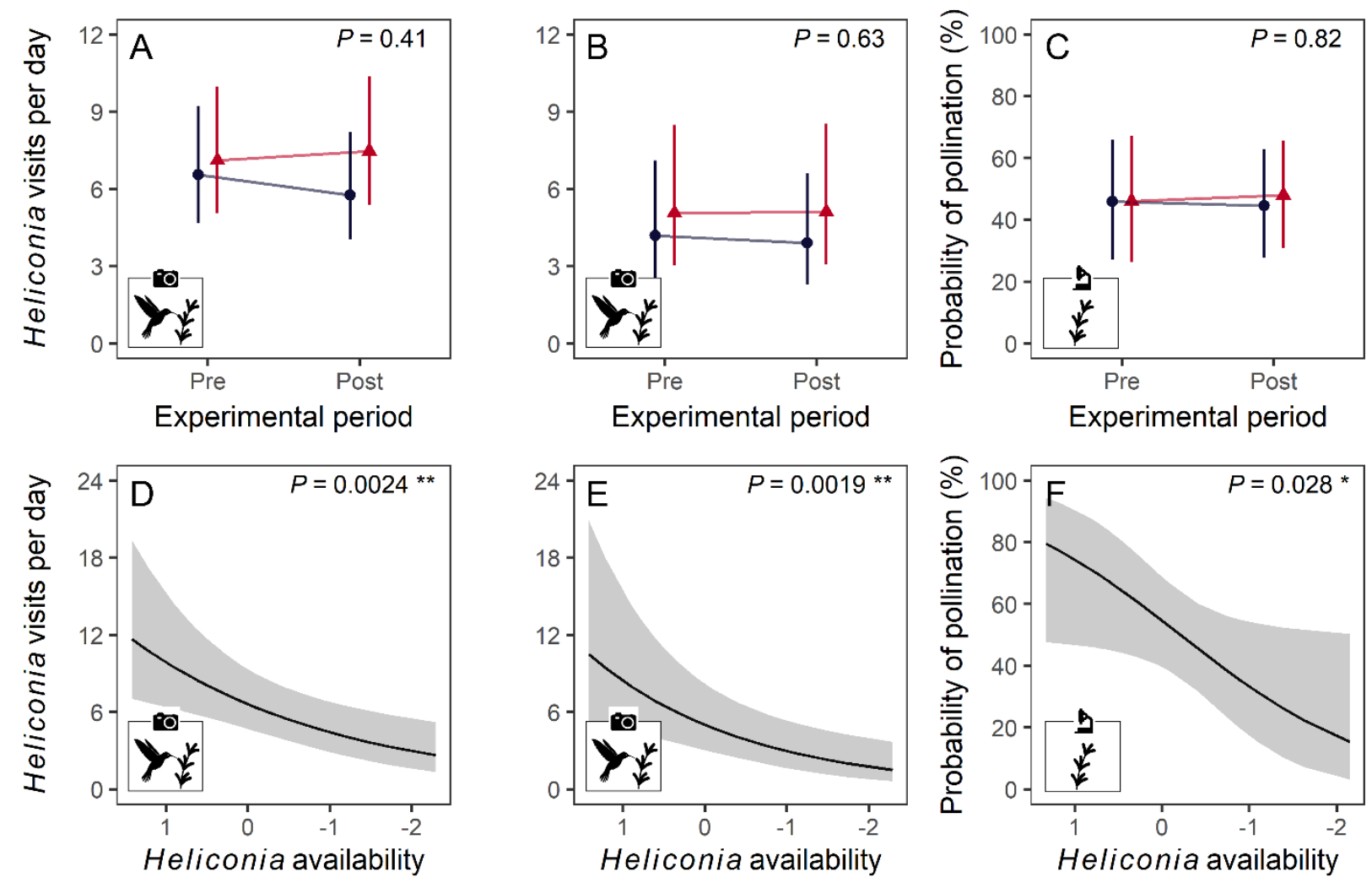

Figure 5. Hummingbird visitation rates to focal Heliconia plants and Heliconia pollination success before and after experimental Heliconia removal (A-C) and across a natural gradient in Heliconia density (D-F). For hummingbird visitation rates, results are shown for the entire

1071 hummingbird community (A, D) and green hermits and violet sabrewings separately (B, E).

1072 Estimated marginal means from GLMMs are presented alongside 95\% confidence intervals. (AC) $P$-values refer to the interaction testing the effect of Heliconia removal, relative to control

1074 replicates; conceptually, a treatment effect is indicated by non-parallel lines. (D-F) Values of 1075 Heliconia availability ( $x$-axis) are standard deviations (1 SD =1.35), with zero representing the 1076 mean log-transformed caloric density (mean $=8)$. Note that the $x$-axis is reversed, such that 1077 declining visitation is associated with declining Heliconia availability. $P$-values refer to the coefficient for Heliconia availability. 
bioRxiv preprint doi: https://doi.org/10.1101/2022.02.24.481682: this version posted Februarv 25. 2022. The copvriaht holder for this preprint (which was not certified by peer review) is the author/funder, who has granted bioRxiv a license to display the preprint in perpetuity. It is made available under aCC-BY-NC-ND 4.0 International license.

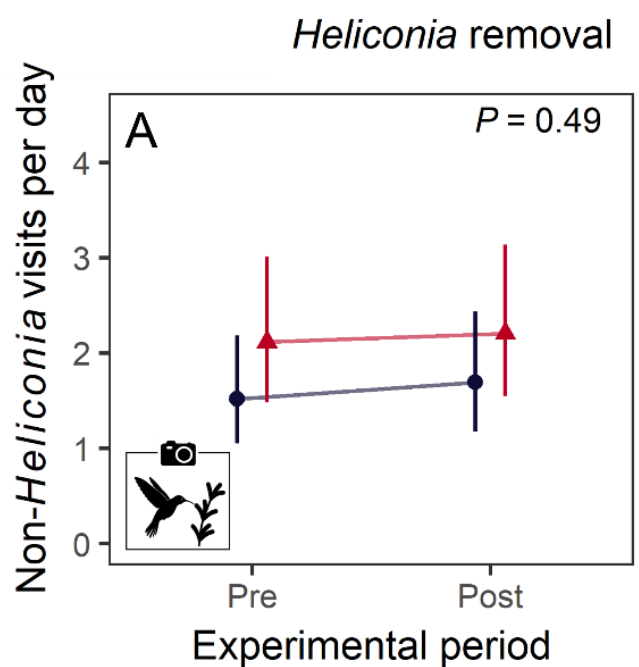

Control $\neq$ Treatment
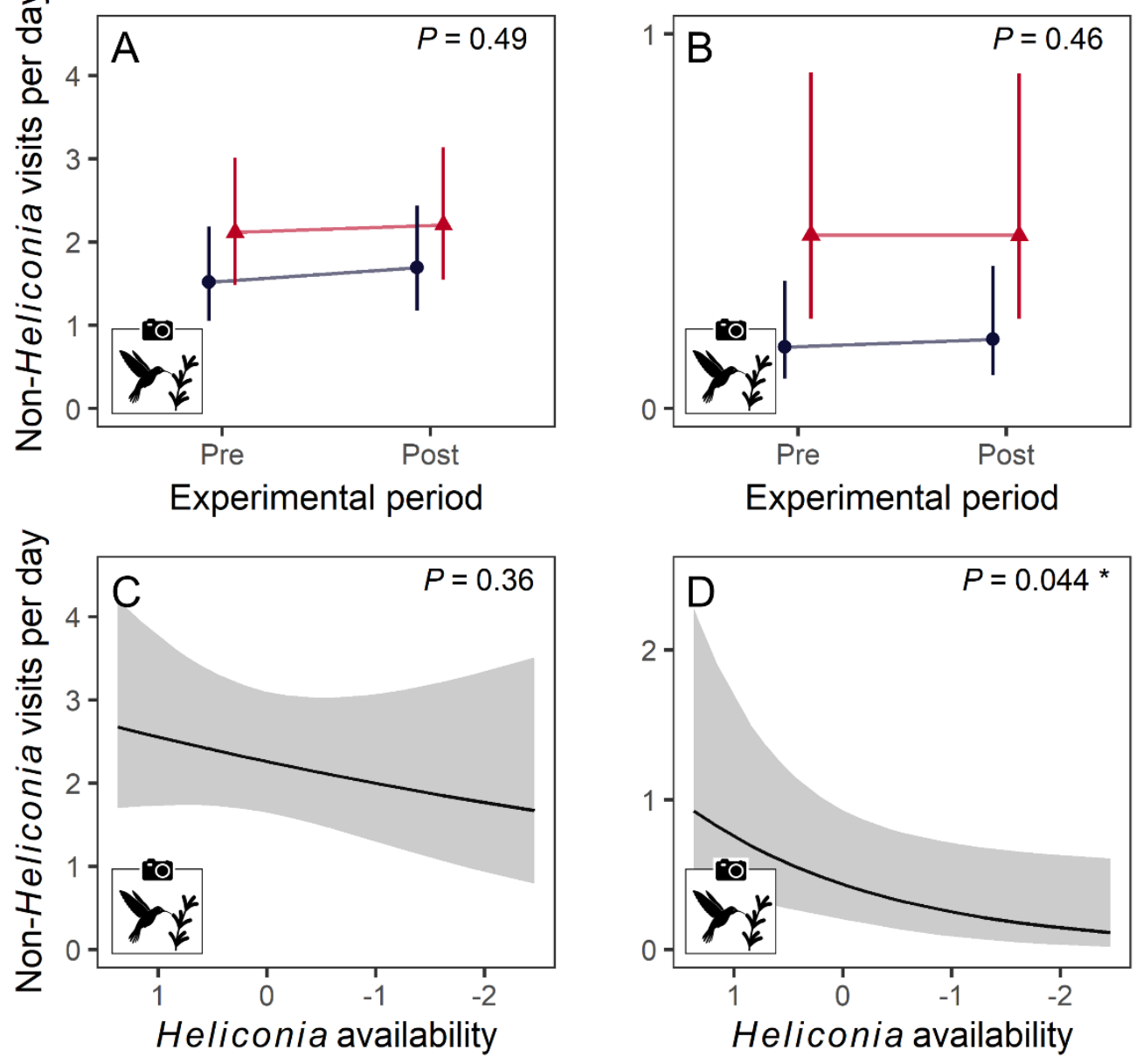
1080 Figure 6. Hummingbird visitation rates to non-Heliconia plant species before and after

1081 experimental Heliconia removal (A-B) and across a natural gradient in Heliconia density (C-D).

1082 Results are shown for the entire hummingbird community $(\mathrm{A}, \mathrm{C})$ and green hermits and violet

1083 sabrewings separately (B, D). Estimated marginal means from GLMMs are presented alongside

$108495 \%$ confidence intervals. (A-B) $P$-values refer to the interaction testing the effect of Heliconia

1085 removal, relative to control replicates; conceptually, a treatment effect is indicated by non-

1086 parallel lines. (C-D) Values of Heliconia availability ( $x$-axis) are standard deviations (1 SD =

1087 1.35), with zero representing the mean log-transformed caloric density $($ mean $=8)$. Note that the

$1088 x$-axis is reversed, such that declining visitation is associated with declining Heliconia

1089 availability. $P$-values refer to the coefficient for Heliconia availability. 